\title{
Mechanisms underlying the autonomic modulation of ventricular fibrillation initiation-tentative prophylactic properties of vagus nerve stimulation on malignant arrhythmias in heart failure
}

\author{
Kieran E. Brack · James Winter · G. André Ng
}

Published online: 8 June 2012

(c) The Author(s) 2012. This article is published with open access at Springerlink.com

\begin{abstract}
Classical physiology teaches that vagal postganglionic nerves modulate the heart via acetylcholine acting at muscarinic receptors, whilst it is accepted that vagus nerve stimulation (VNS) slows heart rate, atrioventricular conduction and decreases atrial contraction; there is continued controversy as to whether the vagus has any significant direct effect on ventricular performance. Despite this, there is a significant body of evidence from experimental and clinical studies, demonstrating that the vagus nerve has an anti-arrhythmic action, protecting against induced and spontaneously occurring ventricular arrhythmias. Over 100 years ago Einbrodt first demonstrated that direct cervical VNS significantly increased the threshold for experimentally induced ventricular fibrillation. A large body of evidence has subsequently been collected supporting the existence of an anti-arrhythmic effect of the vagus on the ventricle. The development of prognostic indicators of heart rate variability and baroreceptor reflex sensitivity-measures of parasympathetic tone and reflex activation respectively-and the more recent interest in chronic VNS therapy are a direct consequence of the earlier experimental studies. Despite this, mechanisms underlying the anti-arrhythmic actions of the vagus nerve have not been fully characterised and are not well understood. This review summarises historical and
\end{abstract}

K. E. Brack · J. Winter · G. A. Ng ( $₫)$

Cardiology Group, Department of Cardiovascular Sciences,

University of Leicester, Leicester LE3 9QP, UK

e-mail: gan1@le.ac.uk

G. A. $\mathrm{Ng}$

Leicester NIHR Biomedical Research Unit in Cardiovascular Disease, Glenfield Hospital, Clinical Sciences Wing,

Leicester LE3 9QP, UK recently published data to highlight the importance of this powerful endogenous protective phenomenon.

Keywords Vagus nerve stimulation - Heart failure . Ventricular fibrillation $\cdot$ Nitric oxide

Sudden cardiac death and the autonomic nervous system

Sudden cardiac death (SCD) resulting from malignant ventricular arrhythmias including ventricular tachycardia (VT) and ventricular fibrillation (VF) represents a significant unsolved clinical problem with an annual death toll of over 325000 people in the USA (Heart Rhythm Foundation [1]) and around 70,000 in the UK (NICE [2]). The search for prophylactic treatments for SCD remains fundamental and is particularly important in heart failure (HF) which is associated with a significantly increased arrhythmic mortality. A distinctive hallmark of HF is that of autonomic disturbance, that is, increased sympathetic activity and decreased parasympathetic tone. Abnormal autonomic function is been described in all aspects of regulation including alterations to afferent nerve activity, central processing, ganglionic and efferent innervation and alterations to the heart itself. Alterations in autonomic activity arise early in the pathogenesis of HF and appear to precede other stereotypical changes. In a canine tachycardia-induced HF model, vagal tone decreased 3 days after the development of cardiac dysfunction, often preceding the enhancement of sympathetic activity [3,4]. Activity of the arterial chemoreceptors [5] and cardiac sympathetic afferent fibres [6] are increased, in part, to drive the increase in sympathetic outflow. Enhanced sympathetic activation occurs before the development of symptoms in 
patients with left ventricular (LV) dysfunction, and reduced parasympathetic drive is present early in patients with symptomatic HF resulting from even mild LV impairment [7].

There is strong evidence that the relationship between impaired neurocardiological control and increased mortality is the result of an increased vulnerability to lethal ventricular arrhythmias [8]. Whilst the clinical and prognostic significance of sympathetic over-activation is well established [9] and forms the rationale for $\beta$-blockers as standard HF therapy, parasympathetic regulation and its modulation has received much less attention. There is, however, important evidence illustrating that the vagus nerve has an antiarrhythmic action in the ventricle. The mechanisms by which the autonomic nervous system, especially its parasympathetic branch, influences ventricular arrhythmias are poorly understood and SCD remains a significant clinical problem. Advances in our ability to treat HF have allowed for significant improvements in patient survival; however, a significant proportion of patients still die suddenly as a result of malignant arrhythmias. Whilst milder forms of heart failure (NYHAs II and III) are associated with lower mortality compared to NYHA IV, the proportion of overall mortality attributable to lethal ventricular arrhythmias is higher [10]. Although there is no direct data exploring this notion, it is tempting to postulate that measures which improve HF status, whilst reducing overall mortality (with pump failure death as main contributor), paradoxically convert patients into a 'more arrhythmogenic' HF phenotype. To achieve further improvements in patient survival, new therapeutic strategies are required to address this. The vagus nerve could provide a powerful endogenous anti-arrhythmic means to achieve such an end. This review aims to discuss historical and recent developments in our understanding of the antiarrhythmic influence of the vagus on the ventricle focussing on the mechanisms of its protective effect. The use of vagus nerve stimulation (VNS) for the prevention of malignant ventricular arrhythmias in HF will be discussed-relating phenotypical changes associated with the syndrome with data on its mechanisms of action.

\section{Parasympathetic tone and patient prognosis}

There is a strong correlation between survival and 'markers' of parasympathetic tone in patients with HF irrespective of $\beta$-blocker therapy [11-13] or following myocardial infarction (MI) [14]. Due to the invasive nature of the direct measurement of vagal activity, studies rely on indirect measurements of sinus node behaviour in the form of heart rate variability (HRV) and baroreceptor reflex sensitivity (BRS). HRV is a measure of the variability of time interval between heart beats (RR interval) and reflects the activity of sympathetic and parasympathetic branches. Several measures of HRV including the standard deviation of the RR interval (SDNN) [15] and the low-frequency component on power spectral analysis [16] are independent risk markers. BRS measures changes in heart rate in response to pressor doses of phenylephrine and/or vasodilatory sodium nitroprusside (SNP) reflecting a reflex pathway primarily involving the parasympathetic nervous system $[17,18]$. BRS is calculated from plots of heart rate or RR interval as a function of the change in blood pressure, the slope of the relationship provides the BRS. The predictive power of indirect measures of parasympathetic activity was first demonstrated in animal studies. A reduction in BRS correlates with an increased occurrence of SCD in animals with healed MI subjected to exercise and acute coronary artery occlusion (CAO) $[18,19]$. Larger studies subsequently revealed BRS to be a strong predictive marker both before MI and after MI, where a depressed BRS predicts a higher risk [20]. Studies of single cardiac vagal fibre activity reveal an increase in vagal activity immediately following CAO occurred in animals destined to survive and that depressed vagally activity in response to changes in blood pressure predicted an increased risk of SCD post-MI [21].

Several small- and large-scale clinical trials have demonstrated the predictive value of BRS and HRV in patient populations. An early prospective clinical study reported that a low BRS was significantly associated with greater all-cause mortality [17], and a subsequent follow-up trial found a strong association between BRS and the occurrence of malignant arrhythmic events but not with all-cause mortality [22]. Several time domain measures of HRV are also reported to be powerful predictor of all-cause mortality following MI [15, 23-25]. Low-frequency (typically < $0.04 \mathrm{~Hz}$ ) power from spectral analysis of RR intervals reflects vagal tone, and its reduction correlates with all-cause mortality and arrhythmic death independent of other factors, for example, left ventricular ejection fraction [16]. The prognostic value of BRS and HRV has been confirmed in large-scale (500-1,000 + patients) randomised clinical trials conducted in patients post-MI (ATRAMI [14]) and in patients with chronic HF (UK-HEART [13]).

\section{The parasympathetic nervous system and ventricular arrhythmias}

The dogma of physiology teaching states that vagal postganglionic nerves modulate the heart through acetylcholine (ACh) acting on muscarinic receptors (mAChRs) to slow heart rate, increase atrioventricular conduction and inhibit atrial force, with little influence on ventricular 
performance. The latter reflects historical reports that ventricular parasympathetic (cholinergic) innervation was sparse. This view is, however, outdated because modern histological techniques reveal a dense and intricate network of ACh containing nerves running over the epi- and endocardial surfaces of left and right ventricles and a widespread distribution of mAChRs throughout the ventricle [26]. More importantly, it is worth reminding readers that the vagal-cholinergic pathway is capable of inhibiting the strong inotropic response to adrenergic activation [27] and as such has a clear functional role. Dense parasympathetic innervation is demonstrated in all species studied including the mouse [28, 29], guinea pig [30], cat [31], dog [32], pig [33], sheep [34] and human ventricle [35, 36] (see Fig. 1).

\section{Parasympathetic innervation and receptors}

The somata of the parasympathetic efferent pre-ganglionic neurones arise chiefly from the ventral lateral region of the nucleus ambiguous, and a smaller proportion from the dorsal motor nucleus and intermediate zone between these sites [37]. Pre-ganglionic fibres are carried within the Xth cranial nerve, that is, the vagi and converge at several atrial and ventricular ganglionated plexuses which regulate cardiac function through post-ganglionic projections postganglionic in the atrial and ventricular tissues. Significant laterality is noted in the effects of the two vagi with the right vagus, exerting a greater influence on the sinoatrial node than the left vagus $[39,40]$ with a greater influence of the left vagus on atrioventricular conduction in the rabbit [38], although significant overlap exists [41]. The existence of laterality is clinically important for the application of VNS where excessive bradycardia should be avoided.

There is a complex network of neuronal subtypes within the ganglionated plexuses which can modulate the heart on a beat-by-beat basis that can act independent of peripheral input [40]. The role of this heart brain, reviewed by Armour [41], is an emerging and fascinating area of research with potential implications in the autonomic modulation of both atrial and ventricular arrhythmias. This is highlighted by evidence that neurochemical stimulation of decentralised intrinsic cardiac neurones can generate atrial and ventricular arrhythmias [42] and that reduced vagal tone in HF may be directly attributable to changes in ganglionic function [43].

Post-ganglionic vagal fibres are primarily cholinergic in nature releasing $\mathrm{ACh}$ which act on $\mathrm{mAChRs}$. Five distinct mAChRs subtypes $\left(M_{1}-M_{5}\right)$ have been described, and 3 subtypes are found within the heart $\left(\mathrm{M}_{2}, \mathrm{M}_{3}\right.$, and $\left.\mathrm{M}_{4}\right)$ [4446]. The most abundant $\mathrm{mAChR}$ is the Gi-protein-coupled $\mathrm{M}_{2}$ receptor and is found on cardiomyocytes [44] and within intracardiac ganglia [47]. Evidence from receptor knockout mice suggests that the $\mathrm{M}_{2}$ receptor subtype is predominantly responsible for regulating cardiac function [45] through a $\mathrm{G}_{\mathrm{i}}$-protein mediated direct action on AChdependent ion channels such as $\mathrm{IK}_{\mathrm{Ach}}$ and indirect effects on inhibition of adenylate cyclase activity that reduces

\section{(A) Ulphani et al - Porcine}

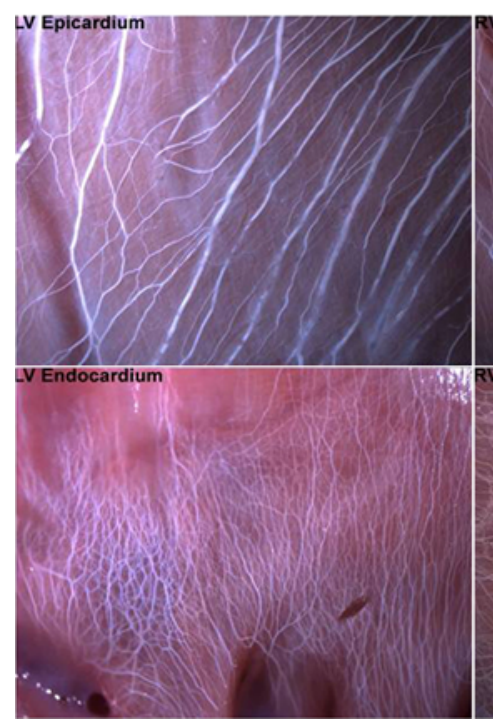

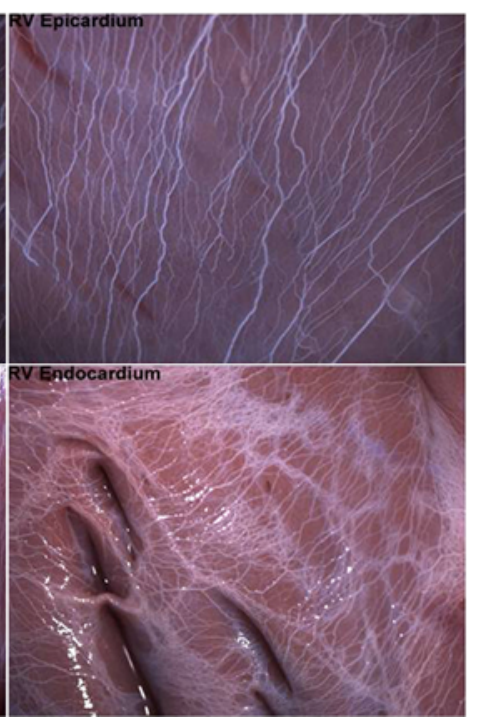

\section{(B) Tagart et al - Canine}

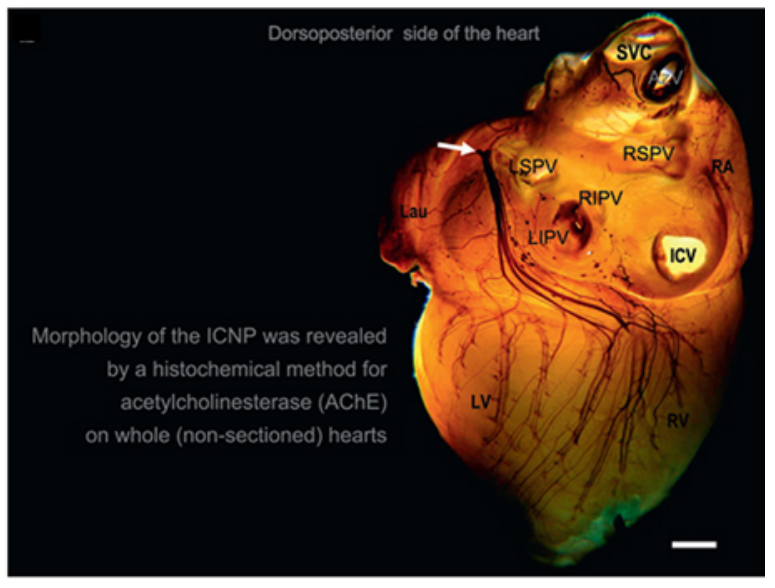

Fig. 1 Parasympathetic innervation of the mammalian ventricles. A composite of images demonstrating extensive parasympathetic innervation of the ventricles of the pig and dog. a Acetylthicholine precipitation demonstrating the gross morphology of parasympathetic fibres innervating the epi- and endocardial regions of the porcine ventricles. b Histochemical staining of acetylcholinesterase containing nerve fibres in the 1-month-old canine heart. Reproduced with permission from Ulphani et al. [33] and Taggart et al. [150] respectively 
intracellular cAMP. cAMP is known to stimulate the nonselective cationic current $\left(I_{f}\right)$ which drives spontaneous depolarisation of pacemaker tissues such as the sinoatrial and atrioventricular nodes and purkinje fibres. The activation of the $\mathrm{IK}_{\mathrm{ACh}}$ results in membrane hyperpolarisation, increasing the cells threshold for firing which contribute to heart rate reduction. $\mathrm{M}_{3}$ and $\mathrm{M}_{4} \mathrm{ACh}$ receptors are [46] preferentially linked with Gq-proteins. The role of the M3 receptor in regulating cardiac function, especially electrophysiology, is discussed later. In addition to ACh, several peptides are co-localised within cholinergic neurones. The most common is vasoactive intestinal peptide (VIP) which is considered to be positively inotropic by increasing adenylate cyclise activity, although this is contentious [48]. It is therefore possible that VIP interacts with ACh at the post-junctional level, opposing the inhibitory actions of $\mathrm{ACh}$ on intracellular cAMP accumulation.

\section{Vagal modulation of arrhythmia susceptibility}

Table 1 presents a summary of studies investigating the effects of VNS on the occurrence of ventricular arrhythmias under a number of conditions. This table aims to summarise the methodological approaches used in each study and to present the results of each study in a condensed but comprehensive format.

\section{Historical perspective}

The first report that VNS reduced the susceptibility of the ventricle to experimental arrhythmia was presented by Einbrodt in 1859 [49], who demonstrated that VF was harder to induce in the dog during stimulation of the vagus. The anti-arrhythmic action of VNS was later reproduced by Scherlag et al. [50] who showed that VNS interrupted the spontaneous occurrence of VT during CAO. Studies by Goldstein et al. [51], Myers et al. [52] and several others [53-56] in the 1970s confirmed the anti-arrhythmic action of VNS. Several studies provide evidence that VNS is protective against experimental-induced VF using undiseased hearts [54-56]. Kent et al. [56] demonstrated a VNSdependent increase in the current required to induce VF, using a train of electrical pulses applied during the refractory period, that is, the ventricular fibrillation threshold (VFT), in the anaesthetised dog. Yoon et al. [55] similarly demonstrated a significant increase in VFT during VNS which was not maintained in the presence of the nonselective $\beta$-adrenergic antagonist propranolol. Similarly, a study by Kolman et al. [54], in which the left stellate ganglion was crushed, demonstrated no anti-arrhythmic effect in control conditions but found significant protection when VNS was applied after stimulation of sympathetic nerves suggesting significant sympathetic-parasympathetic interactions in the anti-arrhythmic action of VNS, which are discussed in later.

A number of studies have shown that VNS prevents arrhythmias as a result of CAO. Myers et al. [52] investigated the effects of low- and high-frequency VNS on spontaneous VF during acute CAO. Vagal stimulation was associated with an intensity-dependent reduction in VF occurrence that was coupled with higher survival rates. These data are supported by Kent et al. [56]. In the converse experiment, Corr and Gillis [57] found that bilateral vagotomy and atropine perfusion increased CAO-induced mortality, suggesting that intrinsic vagal activity was protective. In contrast, Yoon et al. [55] reported no effect of vagal stimulation on VFT in the ischaemic dog heart despite a pronounced response in non-ischaemic controls. A study conducted by Zuanetti et al. [58] demonstrated effects of bilateral vagotomy and of VNS on the occurrence of malignant ventricular arrhythmias (VF or fast sustained VT) following reperfusion of the ischaemic feline myocardium - a reduction in the incidence of both VF and fast sustained VT occurred during VNS whilst bilateral vagotomy resulted in a $55 \%$ reduction in arrhythmia occurrence when compared to unoperated controls.

\section{Studies in a canine model of SCD}

An elegant canine model of SCD developed by Peter Schwartz and colleagues has been used extensively to study the protective effect of the vagus in conscious animals aimed at circumventing the confounding influence of anaesthetics $[19,20,59,60]$. Animals are subjected to ligation of the left anterior descending coronary artery, instrumented for future studies and subsequently allowed to recover for 1 month. Surviving animals go onto a treadmill exercise test with progressively increasing workload together with CAO of the left circumflex artery from the start of the last minute of the exercise regime for a period of $2 \mathrm{~min}$ resulting in the reproducible occurrence of VF in 50-60\% of animals [20,59]. An ischaemia-induced reduction in heart rate in those dogs which survived suggests that active vagal reflexes protect from malignant ventricular arrhythmias. De Ferrari et al. [19] later studied vagal tone in these animals. The authors found that muscarinic blockade with atropine promoted premature ventricular contractions, VT and VF in animals with no arrhythmia during control. The activation of strong vagal reflexes (i.e. HR reduction following CAO) was shown to be important for survival in $25 \%$ of animals studied and was significantly correlated with measures of BRS. Vanoli et al. [60] studied the effects of direct VNS on the occurrence of SCD in dogs that survived MI. Right VNS, applied before and throughout $\mathrm{CAO}$, reduced the occurrence of VF from $92 \%$ in control 


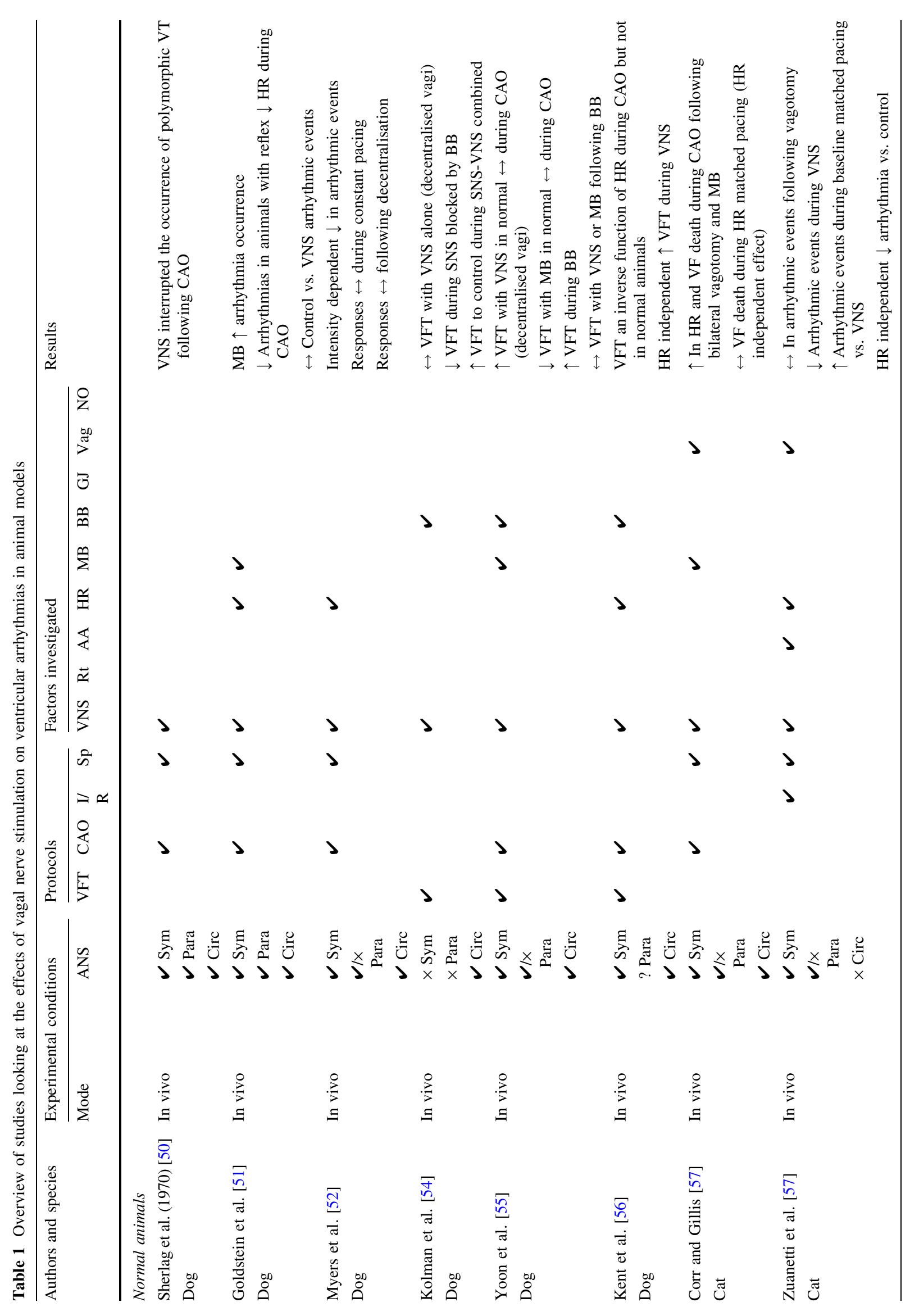




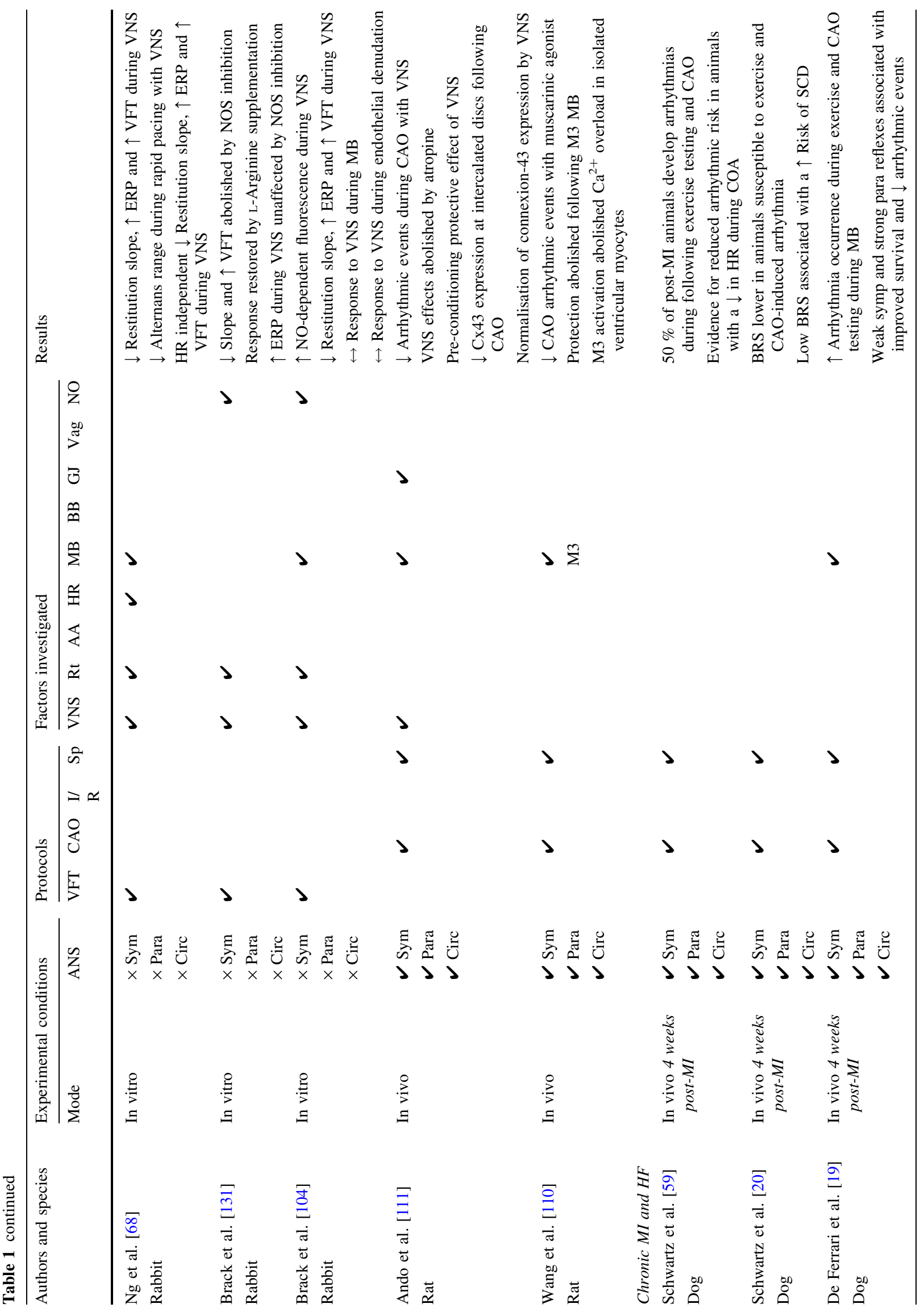




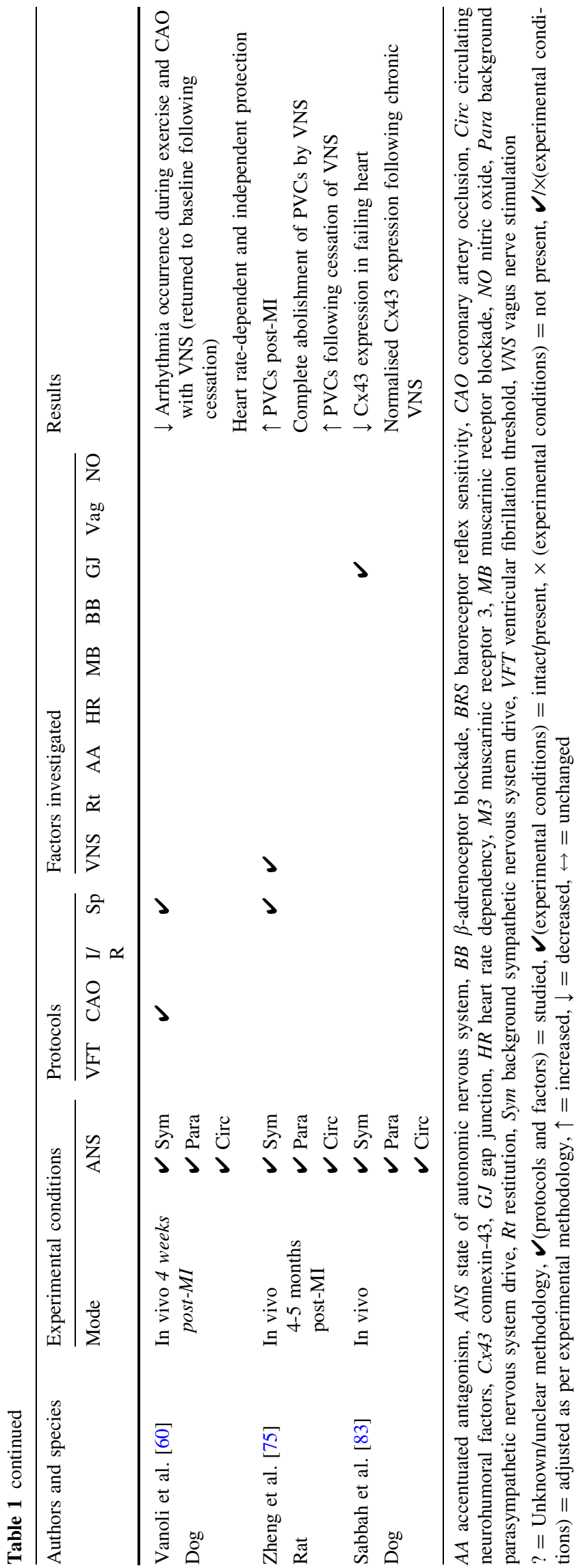

to $10 \%$ during VNS. These data provide strong supportive evidence of the important anti-arrhythmic protection of the vagus nerve on the ventricle.

Studies in the isolated innervated rabbit heart

The onset of VF is believed to be associated with the break-up of spiral waves or rotors into multiple wavelets and oscillations in electrical activity [61]. One mechanism considered key in the development of these oscillations is electrical restitution. Electrical restitution is the relationship between action potential duration (APD) preceding diastolic interval (DI). APD is relatively long at slow heart rates (long DI) but shortens with high heart rates or an ectopic beat (short DI). The magnitude of APD shortening with changes in DI characterises the dynamics of restitution which can be described by the maximum slope during restitution curve (plot of APD vs. DI). The 'restitution hypothesis' proposes that the slope of the APD restitution curve is related to the susceptibility to arrhythmia initiation. Typically oscillations are facilitated when the slope of the APD restitution curve is $>1$ [62]. In situations with a steep restitution curve, a small change in DI leads to a large change in APD and hence dynamic instability and is supported from data from mathematical $[63,64]$ and biological studies $[62,65]$ relating to VF vulnerability [66, 67]. In addition, there is supportive evidence from drugs that reduce restitution slope also prevent VF [65]. Using the isolated innervated rabbit heart preparation, we investigated the effects of VNS on electrical restitution and ventricular fibrillation susceptibility [68]. VNS caused a flattening of the electrical restitution slope, an increase in the current required to induce ventricular fibrillation (increased VFT) alongside a prolongation of MAPD and ERP (see Fig. 2). VFT was inversely correlated with the slope of the electrical restitution curve, in keeping with the restitution hypothesis that predicts an increase in arrhythmia susceptibility as the slope increases. The anti-fibrillatory effect of the vagus nerve occurs in the absence of any background sympathetic activity [38], suggesting a direct anti-arrhythmic effect which is separate from the indirect action concerning antagonism of adrenergic effects (accentuated antagonism), which is evident from single cells studies using pharmacology investigating the effects on individual ionic currents from heart failure preparations [69].

\section{Spontaneous versus induced arrhythmia}

The use of 'spontaneous' and induced methods of arrhythmia occurrence is a contentious issue that warrants discussion. CAO represents one of the most common 

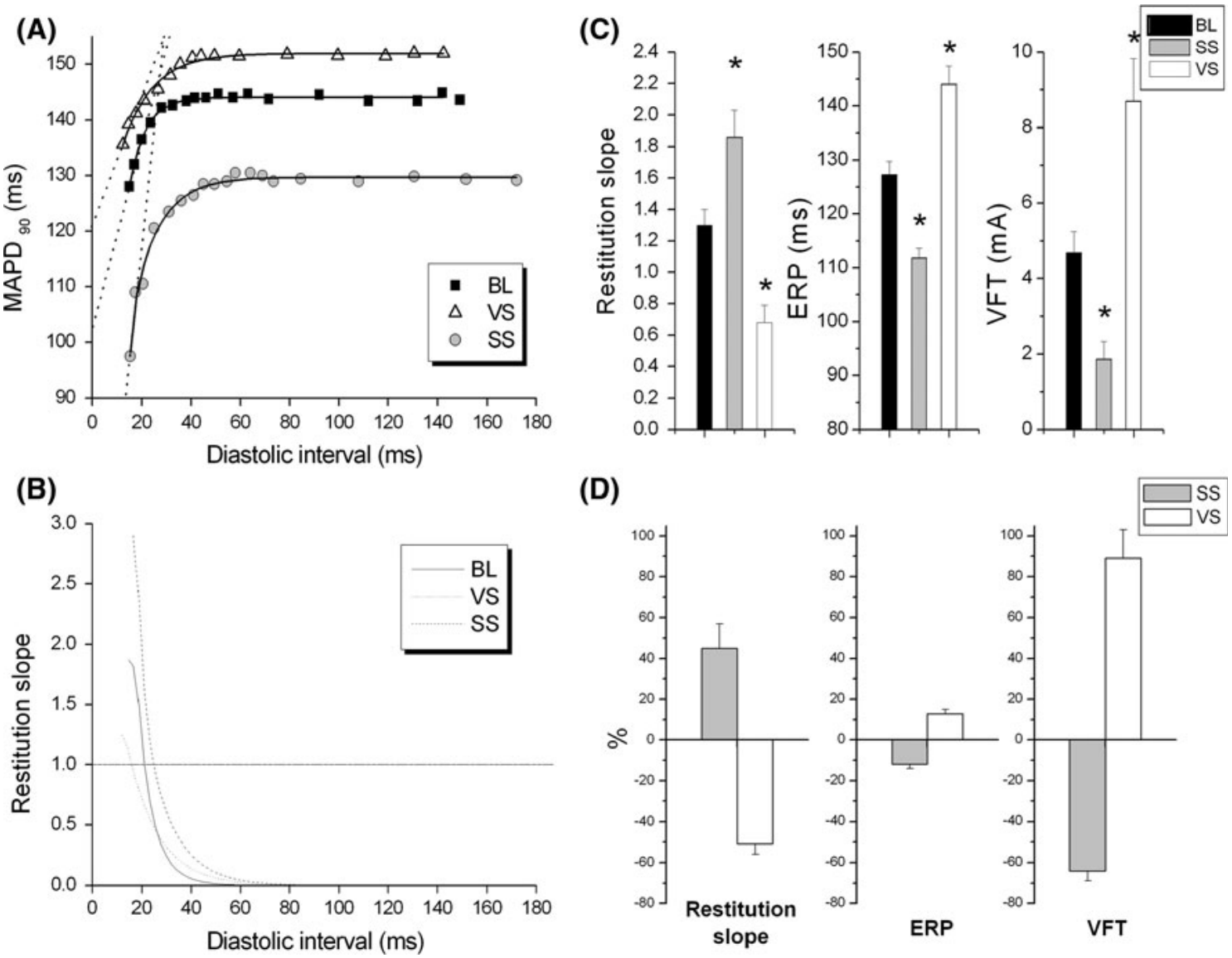

(D)
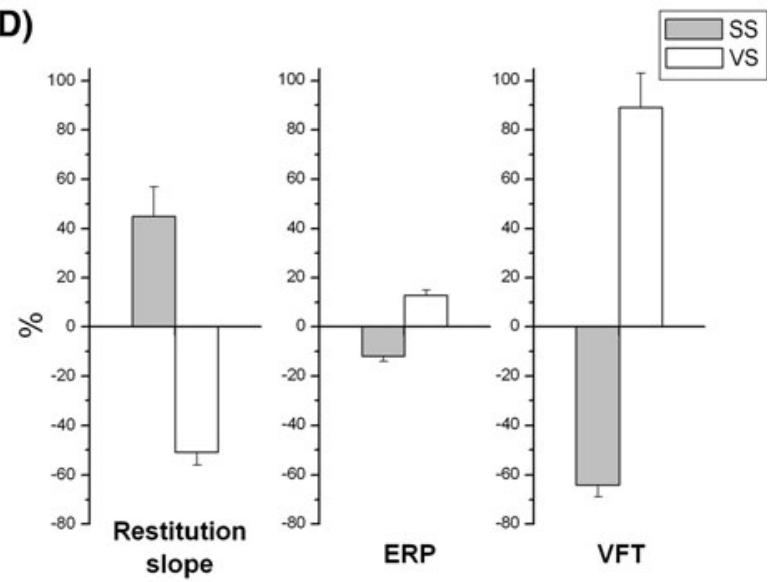

Fig. 2 Autonomic modulation of electrical restitution and ventricular fibrillation threshold. The effects of bilateral sympathetic (SS) and parasympathetic (VS) nerve stimulation on the slope of the electrical restitution curve, effective refractory period (ERP) and ventricular fibrillation threshold (VFT) of the isolated innervated rabbit heart.

$\mathbf{a}$ and $\mathbf{b}$ Data from a single experiment demonstrating the effect of SS and VS on the electrical restitution curve. $\mathbf{c}$ and $\mathbf{d}$ Mean data on the effects of SS and VS on the restitution slope, ERP and VFT. $B L$ baseline. $* P<0.05$; comparison to baseline. Reproduced with permission from $\mathrm{Ng}$ et al. [68]

methodologies to generate arrhythmias which rely on spontaneous arrhythmia generation. Studies utilising CAO often use quantitative measures of arrhythmic events, that is, number of premature ventricular contractions (PVCs), VT and VF or the time course of these events. A disadvantage of this approach is the stochastic nature of arrhythmic event occurrence. The development of the canine model of SCD addressed many of the issues of reproducibility [59]. However, this method is rather timeconsuming, expensive, technically difficult and is highly dependent upon multiple factors, that is, ischaemia and adrenergic activation. Whilst this model could be viewed as physiologically relevant, the assessment and investigation of the direct effects of VNS are not possible. VFT provides a quantifiable and robust measure of arrhythmia susceptibility, allowing that the examination of how physiological, pathophysiological and pharmacological factors can affect electrical stability in addition to effects from nerve stimulation. VFT is widely used for the study of arrhythmia susceptibility and has been shown to predict the

increased and decreased susceptibility of the ventricle to arrhythmias in a range of situations [56, 66, 70]. Some investigators are concerned that VFT does not predict the anti-arrhythmic actions of certain drugs and fails to predict the occurrence of spontaneous arrhythmias [71]. However, Harumi et al. [72] have demonstrated that anti-arrhythmic drugs can be classified depending upon their effects on VFT, ventricular refractoriness and electrical restitution properties, indicative of the multiple mechanisms of action of many of these drugs. Despite these limitations, VFT appears to be a reliable indicator for the effects of the autonomic nervous system on ventricular arrhythmias [55, 56].

\section{Vagus nerve-mediated protection from malignant arrhythmias in heart failure}

Data on the use of vagal stimulation in the treatment for arrhythmia secondary to HF are somewhat limited despite 
the fact that ventricular arrhythmias are responsible for a large proportion of SCDs and that arrhythmic disturbance, that is, ectopic beats or runs of non-sustained ventricular tachycardia, occurs in 50-80\% of all HF patients [73, 74]. The effects of chronic vagal stimulation on arrhythmias occurrence in conscious rats with MI-induced HF were investigated by Zheng et al. [75]. Right cervical VNS conducted 3-5 months post-MI for a period of 7 days prevented the characteristic occurrence of premature ventricular and supraventricular contractions. Sabbah [76] reported on the effects of chronic VNS in dogs with microembolism-induced $\mathrm{HF}$. In these studies, VNS was applied using a negative-feedback loop to maintain heart rate at a level $10 \%$ below baseline for a 3-month period. While the main focus of this study was to look at the effect of VNS on haemodynamics and ventricular remodelling, the effect of VNS on gap junction protein expression was documented. HF causes translocation of the gap junction protein connexin away from the intercalated discs which regulate cell-to-cell excitability, allowing the passage of small ions between adjacent cardiomyocytes. Disruptions to this cell-to-cell coupling play an important role in arrhythmogenesis and underpin conduction through the myocardium. Reduced expression of connexin-43, the primary form expressed in the ventricular myocardium, slows ventricular conduction and increases the dispersion of transmural APD which is linked to the increased incidence of tachyarrhythmias and SCD [77, 78]. VNS therapy reverses the reduction in connexin-43 mRNA and protein expression associated with HF [76], providing strong supportive, yet indirect, evidence that VNS may have antiarrhythmogenic properties in the failing heart. The effects of VNS can be mimicked by the use of pharmacological agents. Pyridostigmine, a cholinesterase inhibitor, decreases the rate of $\mathrm{ACh}$ degradation at the post-ganglionic synapse and prevents the occurrence of single ventricular ectopic beats in patients with HF NYHA class I to III and an ejection fraction of $<45 \%$, although no effect was noted on paired ectopic beats or on the occurrence of periods of ventricular tachycardia [79]. The suppression of cardiac arrhythmias in congestive HF by clonidine [80], a centrally acting $\alpha 2$ adrenoceptor agonist which acts to suppress sympathetic nervous activity, demonstrates how VNS could be used to antagonise the pro-arrhythmic influence of the sympathetic nervous system. Despite limited data on the effects of VNS on arrhythmia susceptibility, there is strong evidence that VNS improves autonomic balance in HF [81, 82], reducing sympathetic hyperactivity and increasing vagal tone, highlighting its potential as an antiarrhythmic therapy.

In addition to its anti-arrhythmic properties, chronic VNS has been shown to reverse the contractile dysfunction and adverse remodelling associated with experimental HF
[81-84] and appears to be beneficial even when applied at subthreshold intensities insufficient to cause changes in HR [85]. The clinical application of chronic vagal therapy is recently described by De Ferrari and Schwartz [85] and will not be discussed in detail here. It is worthy to note that the profound and beneficial effects of the vagus nerve on the cardiovascular system have prompted a number of clinical trials (i.e. INOVATE-HF and NECTAR-HF), examining the application of chronic VNS in the treatment for HF [85]. There is clearly a need for further study on the potential benefit of VNS in the prevention of arrhythmias in HF, especially given that arrhythmia-related deaths remain a significant clinical burden in spite of advances in treatment [10]. Robust clinical trials will be required to truly assess the role of VNS in this regard, but it is possible to speculate how VNS may be beneficial in the treatment for HF on the basis of what we know about the 'disease' process and its phenotypical characteristics.

\section{Mechanisms of the anti-arrhythmic effect of the vagus nerve}

Vagal stimulation modulates ventricular arrhythmias by a number of direct and indirect actions including activation of muscarinic receptors, antagonism of sympathetic actions, heart rate reduction, prolonged APD and reduced APD dispersion, effects on restitution/refractoriness, and possibly via nitric oxide (NO). Several theories describe how alterations in cardiac electrophysiological parameters may influence the generation and propagation of ventricular arrhythmias. Table 2 summarises some of the tentative mechanisms underlying arrhythmogenesis and how the vagus nerve may act via these factors.

\section{Accentuated antagonism}

Interaction between the sympathetic and parasympathetic branches of the autonomic nervous system is complex. Competitive antagonism between autonomic divisions provides an important site of regulation. Samaan [86] first illustrated that vagal stimulation attenuated the chronotropic enhancement associated with sympathetic nerve stimulation (SNS), by demonstrating that the actual change in HR with concomitant VNS and SNS was different to the algebraic sum of the heart rate changes during individual stimulation of each branch. This was later termed 'accentuated antagonism' by Levi and Zieske in [87]. These data demonstrate that the vagus has a powerful antagonistic effect on the chronotropic effect of SNS which is confirmed by others [57]. A similar antagonistic action exists in the control of ventricular performance, intracellular calcium handling and cardiac electrophysiology [87-90]. 
Table 2 Tentative mechanisms by which the vagus nerve can exert anti-arrhythmic action on the ventricle

\begin{tabular}{|c|c|c|}
\hline $\begin{array}{l}\text { Electrophysiological } \\
\text { parameter }\end{array}$ & Relationship to arrhythmias & Modulation by the vagus nerve \\
\hline Electrical restitution & $\begin{array}{l}\uparrow \text { Slope of the electrical restitution curve (APD vs. DI) } \\
\text { Dynamic Instability at short DI } \\
\uparrow \text { Arrhythmic risk } \\
\uparrow \text { Spatial dispersion of restitution } \\
\uparrow \text { Arrhythmic risk }\end{array}$ & $\begin{array}{l}\text { VNS } \downarrow \text { electrical restitution slope } \\
\text { Direct NO-dependent mechanism } \\
\downarrow \text { Symp drive } \\
\quad \downarrow \text { Arrhythmic risk }\end{array}$ \\
\hline Refractoriness & $\begin{array}{l}\uparrow \text { Time course of repolarisation in absence of } \uparrow \text { in APD dispersion } \\
\text { and/or conduction velocity } \\
\downarrow \text { Arrhythmic risk }\end{array}$ & $\begin{array}{l}\text { VNS } \uparrow \text { ERP } \\
\text { Some evidence of uniform prolongation } \\
\quad \downarrow \text { Arrhythmic risk }\end{array}$ \\
\hline APD dispersion & $\begin{array}{l}\uparrow \text { Symp drive } \\
\text { Innervation BASE > APEX } \\
\uparrow \text { APD dispersion } \\
\uparrow \text { Arrhythmic risk } \\
\text { GJ remodelling in ischaemia and HF } \\
\quad \text { Transmural APD dispersion } \\
\uparrow \text { Arrhythmic risk }\end{array}$ & $\begin{array}{l}\text { VNS } \downarrow \text { Symp drive } \\
\quad \downarrow \text { APD Dispersion } \\
\text { Direct VNS } \uparrow \text { APD } \uparrow \text { ERP and } \downarrow \text { VFT } \\
\quad \text { Rate-dependent and independent effects } \\
\text { VNS } \downarrow \text { GJ remodelling } \\
\text { Direct M3 MAChR modulation of GJ }\end{array}$ \\
\hline Conduction & $\begin{array}{l}\text { Gap junction remodelling in ischaemia and HF } \\
\text { Slower conduction } \\
\uparrow \text { Arrhythmic risk }\end{array}$ & $\begin{array}{l}\text { VNS } \downarrow \text { GJ remodelling } \\
\text { Direct M3 MAChR modulation of GJ }\end{array}$ \\
\hline $\begin{array}{l}\text { Intracellular } \mathrm{Ca}^{2+} \text { load } \\
\text { and DADs }\end{array}$ & $\begin{aligned} \uparrow & \text { Symp drive } \\
& \uparrow \mathrm{Ca}^{2+} \text { load in SR } \\
& \uparrow \text { DADs and spontaneous contractions } \\
& \uparrow \text { Arrhythmic risk }\end{aligned}$ & $\begin{array}{l}\text { VNS } \downarrow \text { NA release and cAMP accumulation } \\
\quad \downarrow \mathrm{SR} \mathrm{Ca}^{2+} \text { load } \\
\text { No evidence of direct effect on } \mathrm{Ca}^{2+} \text { handling } \\
\text { in unstimulated ventricular tissue }\end{array}$ \\
\hline $\begin{array}{l}\text { Premature ventricular } \\
\text { contractions }\end{array}$ & $\begin{array}{l}\text { Substrate and trigger for re-entrant arrhythmias } \\
\downarrow \text { Pumping efficiency } \\
\quad \uparrow \text { Symp drive } \\
\quad \uparrow \text { Arrhythmic risk }\end{array}$ & $\begin{array}{l}\text { VNS } \downarrow \text { premature ventricular contractions in } \\
\text { animals with chronic HF } \\
\downarrow \text { Arrhythmic risk }\end{array}$ \\
\hline
\end{tabular}

$A P D$ action potential duration, $C a^{2+}$ calcium, $D A D s$ delayed after depolarisations, $D I$ diastolic interval, $E R P$ effective refractory period, $H F$ heart failure, MAChR muscarinic acetylcholine receptor, NA noradrenaline, NO nitric oxide, SNS sympathetic nerve stimulation, Symp sympathetic, VFT ventricular fibrillation threshold, VNS vagus nerve stimulation

Interaction between the sympathetic and vagal systems occurs via pre- and/or post-junctional mechanisms. ACh binds to mAChRs, on the pre-synaptic sympathetic nerve terminals $\left(\mathrm{M}_{3}\right)$ and $\mathrm{M}_{2}$ receptors on cardiomyocytes to inhibit noradrenaline (NA) release and/or accumulation of intracellular cAMP, respectively [89, 91-94]. With respect to arrhythmogenesis, Kolman et al. [54] reported that the beneficial effects of VNS on ventricular arrhythmia vulnerability were entirely attributed to parasympatheticsympathetic interaction as the protective effect of VNS was abolished by propranolol. Similarly, the anti-arrhythmic effect of VNS in undiseased hearts is abolished by treatment with propranolol [81]. Several investigators have shown a reduction in the anti-arrhythmic effect of VNS following treatment with atropine, supporting the role of muscarinic receptor activation in these studies [77, 81]. It should also be noted that the sympathetic nervous system can regulate the vagal release of $\mathrm{ACh}$ and exerts antagonistic effects at the myocyte level through the actions of NA and co-released neuropeptide Y (NPY) [95-103]. How these signalling pathways are involved in arrhythmogenesis remains to be elucidated.

The role of accentuated antagonism in regulating sympathetic outflow to the heart is nothing new; however, it is particularly relevant to the pathogenesis of HF. HF represents a deleterious spiral of events in which cardiac function declines, necessitating an increase in cardiac output which is mediated through and increase in sympathetic activity. The resulting increase in demand, on an already compromised system, results in further deterioration and a greater requirement for increased sympathetic tone to support cardiac output. By our understanding of sympatheticparasympathetic interaction, if there is an increase in sympathetic activity, there tends to be a reciprocal decrease in parasympathetic tone, as evidenced in studies using HRV and BRS [13, 14]. The beneficial effects of $\beta$-blockade 
therapies in the treatment for HF highlight how antagonising the action of sympathetic nervous system puts a 'brake' on this vicious cycle which improves the quality of life and extends life expectantly [10]. $\beta$-Blockade not only decreases energetic demand in the heart, but, in theory, could reduce the sympathetic antagonism of the parasympathetic nervous system. There is, therefore, an inherent difficulty in attributing beneficial effects of $\beta$-blockade to a single mechanism. In reference to arrhythmias, the benefits appear to be mediated by (1) a reduction in the direct actions of the sympathetic nervous system on the ventricular myocardium, (2) an enhancement of parasympathetic outflow or (3) a combination of these two. As discussed below there are several mechanisms whereby the parasympathetic nervous system directly influences ventricular arrhythmia susceptibility. The use of VNS for the treatment for HF may be viewed as a complementary approach to $\beta$-blockade, whereby vagal tone is increased by direct electrical stimulation. The benefit of VNS on protecting against ventricular arrhythmias may occur through (1) a direct action on of the vagus on the ventricle, (2) antagonism of the actions of the SNS or (3) a combination of these factors. The former is supported by our studies in the isolated innervated rabbit heart, demonstrating a significant anti-arrhythmic action of VNS [68] in the absence of underlying sympathetic nervous activity [38].

\section{Direct muscarinic receptor dependent effects-the $\mathrm{M}_{3}$ receptor}

Several studies have demonstrated that the beneficial effect of the vagus nerve on the occurrence of VF is related to muscarinic receptor activation. Perfusion of atropine, a non-selective muscarinic receptor antagonist, increased the occurrence of CAO-induced VF in several studies [56], including studies conducted in the canine model of SCD [19]. In contrast, we have found that atropine did not abolish the effect of VNS on the VF inducibility in the isolated innervated rabbit heart [103]. This may reflect differences in the methodology of VF induction or species differences in muscarinic receptor distribution, but more importantly the existence of different cellular mechanisms.

Since the discovery of a functional $\mathrm{M}_{3} \mathrm{mAChR}$ in the mammalian myocardium by Jaiswal et al. [105], there have been significant advances in our understanding of the roles of $\mathrm{M}_{3}$ in the control of cardiovascular physiology. The Gq-protein linked $\mathrm{M}_{3} \mathrm{mAChR}$ is known to modulate heart rate and cardiac repolarisation, regulate cell-to-cell communication, be beneficial against ischaemic and oxidative injury, and promote or suppress the formation of arrhythmias in a manner dependent on the location of and/or phenotype of arrhythmia, that is, atrial (increased) versus ventricular (decreased) [106]. Pharmacological activation of $\mathrm{M}_{3}$ receptors reduces the occurrence of ischaemia-, aconitine- and ouabain-induced ventricular arrhythmias [107]. Further to this, over-expression of the $\mathrm{M}_{3} \mathrm{mAChR}$ gene reduces the occurrence of spontaneous arrhythmias in a mouse model of ischaemia reperfusion [108]. The role of the $\mathrm{M}_{3}$ receptor in regulating cardiac repolarisation and cell-to-cell communication is particularly relevant to the discussion of ventricular arrhythmia susceptibility. The $\mathrm{M}_{3}$ receptor activation can stimulate the potassium channel $\mathrm{I}_{\mathrm{KM} 3}$ [109], which has been shown to directly modulate cardiac membrane repolarisation [110]. Studies in isolated cells suggest that $\mathrm{M}_{3}$ activation reduces calcium overload in ventricular myocytes, and it has been proposed that this action mediates its protective action in ischaemia-induced arrhythmias [110]. In addition, the $\mathrm{M}_{3}$ receptor appears to regulate the expression of phosphorylated connexin-43 (Cx43), a gap junction channel protein highly expressed in ventricular tissue and reduced in ischaemia and HF. Efferent vagal nerve stimulation may protect the heart form ischaemia-induced arrhythmias by preventing a reduction of phosphorylated Cx43 associated with ischaemia [111]. Similarly chronic therapy with VNS appears to normalise the expression of $\mathrm{Cx} 43$ within the left ventricular myocardium of dogs with HF [83].

Evidence from studies in gene knockout mice suggests that the effects of $M_{3}$ activation oppose those of the $M_{2}$ receptor, to enhance contractility and increase heart rate [45]. It is recognised that the $\mathrm{M}_{3}$ receptor promotes arrhythmias in atrial tissues but suppresses ventricular arrhythmias (a likely result of opposing effects on repolarisation time course), which may indicate difference in the distribution of the mAChRs throughout the myocardium or regional variations in ion channel expression (e.g. greater $\mathrm{IK}_{\mathrm{ACh}}$ in atrial tissues). Importantly, the expression of $\mathrm{M}_{3}$ appears to be increased in hearts from patients with congestive heart failure [106]. Whilst pharmacological evidence supports the anti-arrhythmic role of the $M_{3}$ receptor, its contributions to the action of the vagus nerve remain to be elucidated.

Heart rate reduction and ventricular refractoriness

An obvious consideration when stimulating the vagus nerve is the resulting bradycardia. Some studies suggest that the anti-arrhythmic influence of the vagus nerve is reduced but not abolished when the heart rate is controlled [51, 52, 56, 58]. We have shown that the anti-VF effect of VNS is preserved during constant pacing in the isolated innervated rabbit heart [38]. In addition, we have shown that despite differential heart rate effects of left and right VNS, the anti-fibrillatory effect is equipotent [38]. The mechanisms by which a reduction in heart rate could protect from ventricular arrhythmias is not understood, but 
may include rate-dependent alterations in ventricular APD, refractoriness and dispersion of both factors. It is widely recognised that VNS prolongs ventricular APD and ERP $[38,104,112,131]$. The direction of change in ERP during autonomic nerve stimulation mimics the change in VFT [38]. Using optical mapping of ventricular APD, we have shown that bilateral VNS reverses the sequence of ventricular repolarisation [113] although it is not clear how this might be cardioprotective. Detailed study on the effects of VNS on ventricular repolarisation is clearly needed. A similar anti-fibrillatory action has been noted when porcine hearts are treated with Ivabradine, an inhibitor of the pacemaker current $\left(I_{f}\right),[114]$ though it is not clear whether this is a consequence of induced bradycardia or from nonspecific effects on other ion channels [115].

A common finding of clinical trials on HF is a negative correlation between heart rate and patient survival and the ability to increase heart rate in response to exercise [116]. The relationship between heart rate and mortality holds true in untreated patients and in those receiving $\beta$-blockers, although a reduction in heart rate and risk is seen in the latter. High heart rate is associated with cardiovascular risk by a number of independent factors (e.g. increased ventricular wall stress, decreased arrhythmic threshold) and factors which are related to adrenergic hyperactivity (i.e. left ventricular hypertrophy, lower arrhythmic threshold) [116]. VNS provides a mechanism, in addition to $\beta$-blockade, to reduce heart rate in these high risk patients; however, a large reduction in heart rate may not be ideal as excessive bradycardia carries its own potential risk. As with other studies, it is difficult to assess the relative contribution of different factors (i.e. heart rate reduction and direct electrophysiological effects) to the overall risk of higher heart rates, especially in regards to $\beta$-blockade and VNS with their multiple sites of action.

The relative importance of bradycardia as a protective mechanism is unclear and contrasts with our findings that the effects of VNS are preserved during constant ventricular pacing. VNS still has a profound effect on ventricular electrophysiology during constant pacing, reducing susceptibility to VF [38]. Studies conducted in 1952 by Silvo Weidmann [117] first demonstrated the role of time course of repolarisation in the excitability of Purkinje fibre and demonstrated that the membrane potential needed to return to at least $-55 \mathrm{mV}$, following a triggered action potential, before another action potential could be elicited [117]. The electrophysiological implication of this is that factors (i.e. pharmacological, physiological) which shorten the time course of repolarisation are likely to be arrhythmogenic. Studies using anoxia and acetylcholine, the latter in atrial tissue, support this conclusion, accelerating repolarisation and promoting arrhythmia generation [118]. Increases in ERP, occurring without significant changes in conduction velocity, may provide protection from re-entrant arrhythmias although this may only be true if APD prolongation is uniform across the ventricular surface, as appears to be the case during VNS in the dog [112] but not in our studies in the innervated rabbit heart [113]. Several class III antiarrhythmic compounds, such as amiodarone and sotalol, prolong phase 3 of the cardiac action potential and are recognised to reduce the occurrence of atrial and ventricular arrhythmias [119], although these compounds affect several different aspects of cardiac electrophysiology.

Another important concept in the generation of ventricular arrhythmias is that of action potential duration dispersion. Spatial repolarisation heterogeneity provides a substrate for the generation of ventricular arrhythmias, and dispersion of APD is a known mechanism underlying circus movement re-entry around refractory regions [120]. Although previous investigators have noted that the effects of VNS on electrophysiology are uniformly distributed [112], with no effects of APD dispersion, it is known that the SNS promotes a greater degree of APD shortening in basal regions of the ventricle [121], data which are supported by histological studies of sympathetic nerve distribution $[122,123]$. When there is a background sympathetic tone, VNS may prevent arrhythmias by antagonising sympathetic mediated changes in spatial repolarisation (see accentuated antagonism). This idea may be particularly relevant in HF where there is an increased activation and influence of the sympathetic nervous system.

\section{Nitric oxide}

The biosynthesis and multitude of biological functions of nitric oxide (NO) have been reviewed extensively elsewhere [123-127]. Our discussion will focus on the role of NO in relation to the parasympathetic nervous system.

\section{Direct NO-dependent effects on arrhythmia susceptibility}

It is widely accepted that NO is involved in both central and peripheral aspects of vagal control, not only in terms of cardiac function but also in other bodily systems such as the GI tract [128]. In the heart, NO appears to modulate the actions of the parasympathetic nervous system, regulating the change in HR in response to parasympathetic stimulation [129]. Herring et al. [130] suggested that NO acts presynaptically to reduce the bradycardic response to VNS. Other investigators have noted that NO modulates changes in A-V conduction in response to VNS in a similar manner [129] and suggests that NO has a role in the ventricular effects of VNS. We directly tested this possibility using the innervated rabbit heart.

After confirming the anti-VF effect of VNS together with an increase in ERP and reduction in the slope of the 
restitution curve, we perfused the innervated heart preparation with the non-specific nitric oxide synthase (NOS) inhibitor L-NA and investigated the effects of VNS. In the presence of L-NA, the increase in VFT and flattening of electrical restitution slope with VNS were abolished whilst the increase in ERP was preserved [131] (see Fig. 3). The response to VNS was restored by supplementation with LArginine, the NO substrate which competes with L-NA for binding to NOS. This anti-arrhythmic effect of NO is supported by the work of Kumar et al. [132], who demonstrated that exogenous intrapericardially applied nitroglycerine significantly reduced the occurrence of ischaemia-induced VF. We later showed that NO donor, sodium nitroprusside, increased VFT, ERP and reduced the slope of the restitution curve in a similar manner to VNS [133]. These data tentatively show that (1) electrical restitution is important as a mechanism during VNS protection from VF as the effects of restitution and VFT parallel one another, (2) vagally mediated changes in perfusion pressure, heart rate and ERP do not appear to be significantly involved in vagal protection against $\mathrm{VF}$ as the changes are disproportionate in comparison with the changes in VFT and restitution, and (3) NO plays a key role in this protective effect.

Although the aforementioned study provides basis for a working hypothesis for NO in mediating the ventricular effects of the vagus, it provided only indirect evidence of this mechanism. Through the use of the NO-sensitive dye DAF-2 DA, we were able to provide direct evidence of VNS-mediated NO release [134]. NO-dependent fluorescence was found to increase during both left and right cervical VNS in relation to the intensity of stimulation (see Fig. 4). Perfusion of L-NA significantly decreased background fluorescence, indicative of a reduction in basal NO production (presumably from the endothelium), and abolished the increase in fluorescence seen with VNS. TRIM, a specific antagonist of the neuronal form of NOS (nNOS or NOS I), had no effect on background fluorescence but abolished the fluorescence increase with VNS supporting the notion that NO production during VNS occurs through nNOS.

More recently, we have extended these findings to show that these effects of the vagus do not occur through activation of mAChR's since perfusion with atropine at a concentration sufficient to block changes in heart rate and ERP did not influence the vagal effect on DAF-2 fluorescence, the reduction of the slope of the electrical restitution curve or increase in VFT [104]. In addition, this study indicates that the protective effects do not involve the endothelium (a substantial source of NO in the heart) as effects are preserved after functional endothelial denudation or during inhibition of vasoactive intestinal peptide (VIP) which is a neuroactive peptide released together with ACh.
It has previously been suggested that vagally released $\mathrm{ACh}$ and NO can act through parallel independent signalling pathways [135]. Given our evidence that NO production during VNS occurs through nNOS independent of the endothelium, VIP or $\mathrm{ACh}$, we tentatively propose the existence of a separate network of parasympatheticnitrergic anti-fibrillatory neurones [136] within the ventricle. It is known that nNOS is present in many parasympathetic neurones innervating the heart $[137,138]$, and there is also evidence of a subpopulation of intracardiac nerve fibres that contain solely NO coursing towards the ventricle in humans, providing supportive evidence for our hypothesis [139]. Given recent demonstrations of significant populations of parasympathetic innervation in the ventricles of mammalian species, refuting the classical view of sparse innervation, detailed neuro-anatomical information on the chemical phenotype of parasympathetic nerves within the ventricle is warranted.

\section{VNS, NOS expression and NO signalling}

NOS expression is found in endothelial cells, myocytes and neuronal cells, and it regulates a huge range of biological functions in a manner which appears to be dependent upon location [124-127]. The relative expression of the different NOS isoforms is altered significantly in both experimental and human HF, and dysfunction of NO signalling may be causally associated with many pathological changes associated with HF (i.e. reduced contractile function). Importantly studies conducted in dogs with microembolism-induced HF demonstrate that chronic VNS normalises both mRNA and gene expression of NOS [83]. Information on how alterations of NOS expression may alter ventricular arrhythmia susceptibility is currently lacking. Moreover, studies on the role on the NO-dependent anti-fibrillatory effects of VNS have not been carried out in failing hearts. Further studies are required to address the role of alterations in NO signalling and NOS expression in ventricular arrhythmia susceptibility and how VNS may modulate these mechanisms.

Role of intracardiac neuronal networks and afferent nerve activation

It is recognised that direct neurochemical stimulation of decentralised intrinsic cardiac neurones can generate atrial and ventricular arrhythmias [42] and that the attenuation of parasympathetic control in HF may in part relate to changes in ganglionic function, as demonstrated in dogs with pacing induced HF [43]. Whether VNS can reverse these changes or modulate the intrinsic neuronal network to modify arrhythmia susceptibility is unknown.

Sensory (or afferent) nerve fibres relay information from the myocardium to the brain for processing, and 

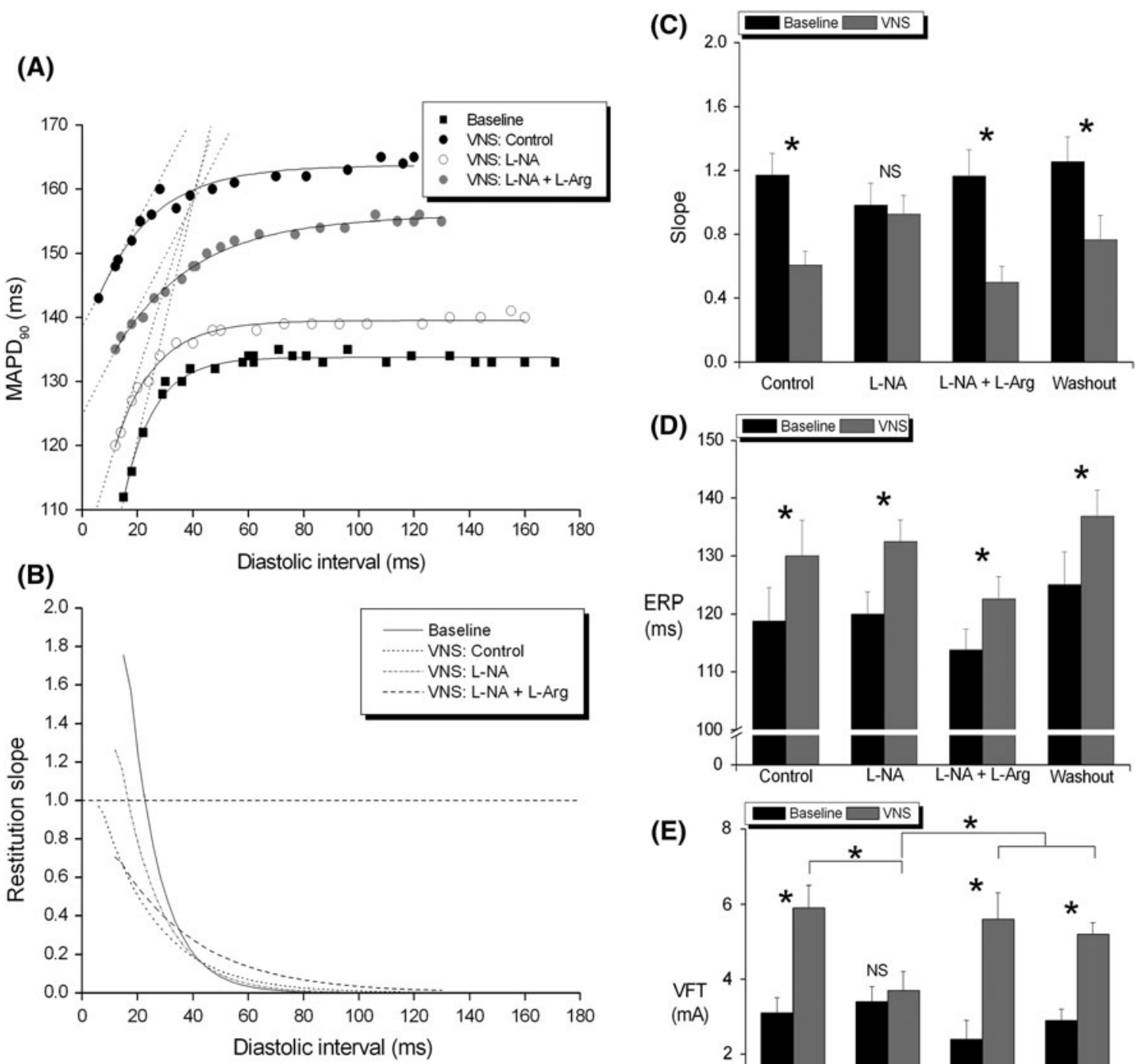

(E)

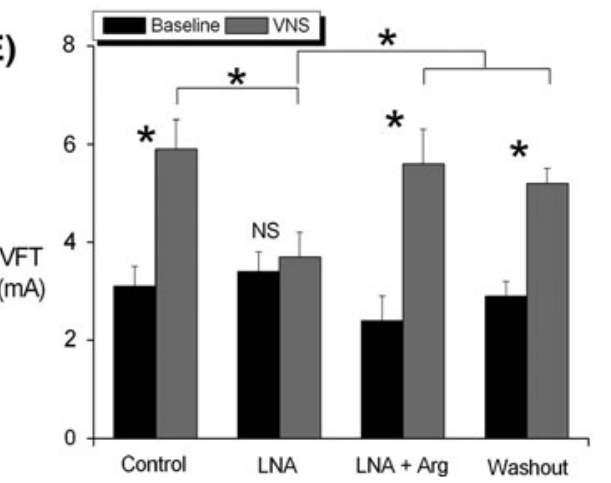

Fig. 3 A direct nitric oxide synthase(NOS)-dependent anti-arrhythmic influence of vagus nerve stimulation. NOS-dependent antiarrhythmic influence of vagus nerve stimulation (VNS) in the isolated innervated rabbit heart. a and b Data from a single experiment demonstrating how the influence of VNS on the restitution slope is abolished by perfusion with L-NA and restored by L-arginine (L-Arg).

approximately 70 and $80 \%$ of the vagus nerve consists of these afferent fibres. Therefore, electrical stimulation of the vagus may capture both afferent and the effector efferent nerves, unless selective stimulation protocols, such as anodal block, are used to exclude a specific population of neurones. The contribution of these distinct populations of nerves to the anti-arrhythmic benefits of VNS is currently unknown. Studies conducted in our laboratory with the innervated rabbit heart show that the protective effect of VNS is not dependent upon the brain, but these experiments do not exclude the existence of additional c, $\mathbf{d}$ and e Mean data effects of L-NA and L-NA + L-Arg on VNS induced changes in restitution slope, effective refractory period (ERP) and ventricular fibrillation threshold (VFT), respectively. $* P<0.05$; comparison to baseline or between groups. Reproduced with permission from Brack et al. [104]

anti-arrhythmic mechanisms in vivo or afferent reflex responses which can occur locally [38]. An earlier study rules out antidromic afferent nerve stimulation as a potential mechanism, since the response is lost during perfusion of the ganglionic transmission inhibitor hexamethonium. Myers et al. [52] demonstrated that the protective effects of VNS were maintained following decentralisation of the vagus nerve, but quantitative comparison of responses between groups was not carried out. Afferent nerve activation provides a, speculative, 'explanation' of the beneficial effects of chronic low-intensity 
Fig. 4 Direct measurement of NO release during vagus nerve stimulation. Measurement of nitric oxide release during cervical vagal nerve stimulation (VS), using the fluorescent indicator DAF2-DA, in the isolated innervated rabbit heart. a Raw data from a single experiment illustrating the change in left ventricular pressure (LVP), aortic perfusion pressure (AP) and nitric oxide dependent florescence (F490) during low-, medium- and highintensity VS. b and $\mathbf{c}$ Mean data demonstrating the change in F490 before, during and after individual left and right VS. ${ }^{*} P<0.05, * * P<0.01$, $* * * P<0.001 ;$ comparison with steady-state response or between intensities of stimulation. Reproduced with permission from Brack et al. [134]

(A)

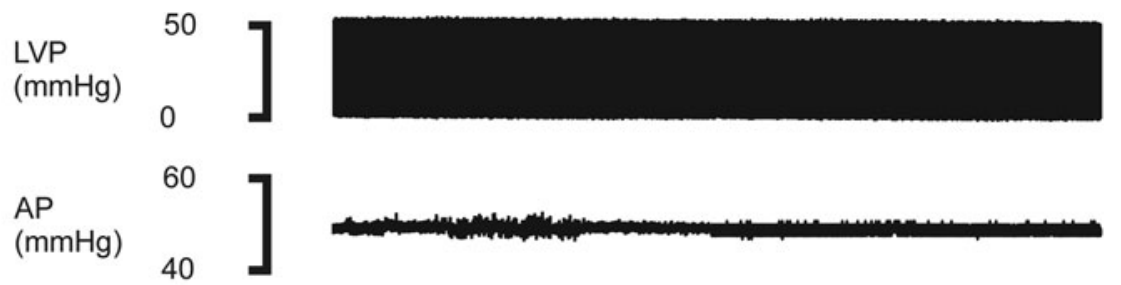

F490

(V)
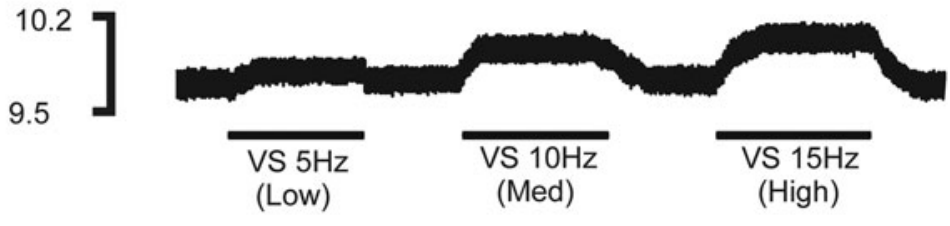

30s

(B)

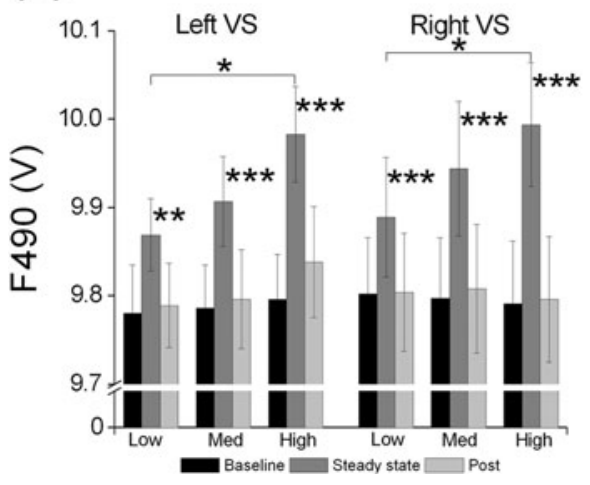

(C)

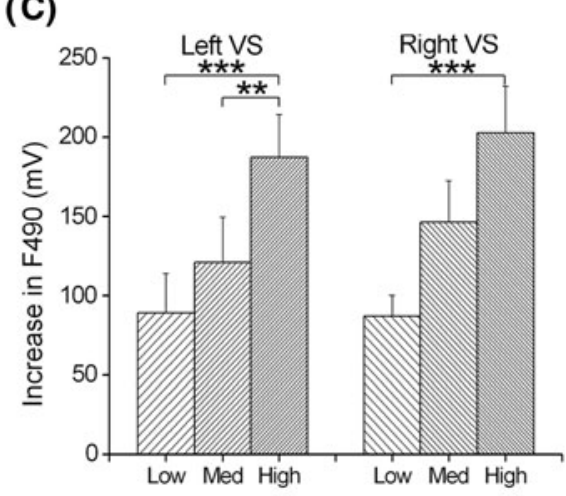

VNS on haemodynamic parameters and remodelling in experimental HF (i.e. where no change of cardiac rate is seen) [84]. Afferent nerve activation and the modulation of central processes controlling autonomic outflow is a distinct possibility which requires attention.

Role of vagal activated anti-inflammatory pathways

Another mechanism by which the parasympathetic nervous system may protect the heart is via an anti-inflammatory action. It has become increasingly evident over the two decades that inflammatory responses can be modulated and feedback into the autonomic nervous system, the so-called inflammatory reflex [140]. Locally released cytokines can activate sensory fibres which relay information to the central nervous system influencing efferent signals (refs). Vagotomy has a pronounced effect on the cytokine response to injury and $\mathrm{ACh}$, acting through nicotinic $\mathrm{ACh}$ receptors, can inhibit the release of several cytokines [141]. The intracellular signalling pathways mediating this response have been reviewed by $\mathrm{Li}$ and Olshansky [142]. Interestingly, a strong inverse correlation between HRV and levels of inflammatory cytokines was report in a trial examining coronary artery risk in young adults [143]. Lower levels of cytokines are associated with a restricted inflammatory response in following $\mathrm{MI}$ and in $\mathrm{HF}$, where it is recognised that arrhythmias contribute to a significant proportion of deaths.

The role of inflammation in the generation of arrhythmias in HF and following ischaemic injury is not clear, but it is recognised that malignant arrhythmias are more likely in patients with acute and chronic myocarditis [144, 145]. Cytokines can exert a direct action on myocyte electrophysiology but can also indirectly increase the susceptibility of the heart to arrhythmias by promoting the formation of non-conductive scar and fibrotic tissue, hypertrophy and atrophy of myocytes and impairment of oxygen availability [146]. Mice engineered to over-express tumour necrosis factor- $\alpha$ have been commonly used as a model of congestive HF, exhibiting a large number of ion channel conductance abnormalities and increased susceptibility to induced arrhythmias compared to wild-type controls [147-149]. Animals with TNF- $\alpha$-induced failure exhibit a number of different types of arrhythmia, included atrial tachycardia, AF, non-sustained VT and ventricular ectopy, have altered repolarisation characteristics and dysregulated intracellular calcium homoeostasis [147]. Further study is warranted into the role of cytokines in arrhythmias and the potential role of the vagus in modulating this process. More detailed information on how 
inflammatory pathways may modulate ventricular electrophysiology is required and represents an area of some interest. It is possible that these studies could provide novel targets for the treatment for ventricular arrhythmias in HF and other arrhythmogenic conditions (i.e. long QT syndrome). It is recognised that inflammatory pathways may play an important role in the remodelling of the ventricles in HF [146] and that VNS can prevent/normalise ventricular phenotype in conjunction with the suppression of inflammatory activation. The structural abnormalities associated with ventricular remodelling (i.e. fibrosis and hypertrophy) may contribute to increased arrhythmic risk, and it is likely that VNS-mediated suppression of these pathways is a contributing factor to the anti-arrhythmic action of chronic VNS therapy in HF. This idea differs from the direct role of inflammatory mediators in arrhythmia susceptibility.

\section{Conclusions}

The profound anti-arrhythmic influence of the vagus nerve has provided modern clinical practice with valuable tools for assessing risk in the form of HRV and BRS, and chronic VNS may prove to be a powerful therapy for heart failure. The effects of the vagus nerve on ventricular arrhythmogenesis are multi-faceted involving effects on heart rate, interactions with the sympathetic nervous system, anti-inflammatory influences and a direct effect on ventricular electrophysiology. Our data indicate that the vagus nerve exerts a direct anti-arrhythmic action at the level of the ventricles through the release of NO-a tentative-independent nitrergic neural network regulating cardiac physiology which could potentially offer a novel therapeutic avenue.

Acknowledgments KEB is supported by a British Heart Foundation Intermediate Basic Science Fellowship (FS/12/2/23900). JW was supported on a British Heart Foundation project grant (PG/09/039).

\section{Conflict of interest None.}

Open Access This article is distributed under the terms of the Creative Commons Attribution License which permits any use, distribution, and reproduction in any medium, provided the original author(s) and the source are credited.

\section{References}

1. The Heart Rhythm Foundation (2012) Sudden cardiac arrest key facts. Heart Rhythm Society. http://www.heartrhythmfounda tion.org/facts/scd.asp. Accessed 1st February 2012

2. The National Institute for Clinical Excellence (2007) Implantable cardioverter defibrillators for arrhythmias. http://www.nice. org.uk/nicemedia/live/11566/33167/33167.pdf. Accessed 1st February 2012

3. Ishise H, Asanoi H, Ishizaka S, Joho S, Kameyama T, Umeno K, Inoue H (1998) Time course of sympathovagal imbalance and left ventricular dysfunction in conscious dogs with heart failure. J Appl Physiol 84:1234-1241

4. Motte S, Mathieu M, Brimioulle S, Pensis A, Ray L, Ketelslegers JM, Montano N, Naeije R, van de Borne P, Entee KM (2005) Respiratory-related heart rate variability in progressive experimental heart failure. Am J Physiol Heart Circ Physiol 289:H1729-H1735

5. Sun SY, Wang W, Zucker IH, Schultz HD (1999) Enhanced activity of carotid body chemoreceptors in rabbits with heart failure: role of nitric oxide. J Appl Physiol 86(4):1273-1282

6. Ma R, Zucker IH, Wang W (1997) Central gain of the cardiac sympathetic afferent reflex in dogs with heart failure. Am J Physiol 273:H2664-H2671

7. Grassi G, Seravalle G, Bertinieri G, Turri C, Stella ML, Scopelliti F, Mancia G (2001) Sympathetic and reflex abnormalities in heart failure secondary to ischaemic or idiopathic dilated cardiomyopathy. Clin Sci (Lond) 101:141-146

8. Schwartz PJ (1998) The autonomic nervous system and sudden death. Eur Heart J 19(Suppl F):F72-F80

9. Floras JS (2003) Sympathetic activation in human heart failure: diverse mechanisms, therapeutic opportunities. Acta Physiol Scand 177:391-398

10. Hjalmarson A, Goldstein S, Fagerberg B, Wedel H, Waagstein F, Kjekshus J, Wikstrand J, El Allaf D, Vitovec J, Aldershvile J, Halinen M, Dietz R, Neuhaus K-L, Janosi A, Thorgeirsson G, Dunselman PHJM, Gullestad L, Kuch J, Herlitz J, Rickenbacher P, Ball S, Gottlieb S, Deedwania P, for the MERIT-HF Study Group (2000) Effects of controlled-release metoprolol on total mortality, hospitalizations, and well-being in patients with heart failure: the metoprolol CR/XL randomized intervention trial in congestive heart failure (MERIT-HF) JAMA 283:1295-1302

11. Nolan J, Batin PD, Andrews R, Lindsay SJ, Brooksby P, Mullen M, Baig W, Flapan AD, Cowley A, Prescott RJ, Neilson JM, Fox KA (1998) Prospective study of heart rate variability and mortality in chronic heart failure: results of the United Kingdom heart failure evaluation and assessment of risk trial (UK-heart). Circulation 98:1510-1516

12. La Rovere MT, Pinna GD, Maestri R, Robbi E, Caporotondi A, Guazzotti G, Sleight P, Febo O (2009) Prognostic implications of baroreflex sensitivity in heart failure patients in the betablocking era. J Am Coll Cardiol 53:193-199

13. Nolan J, Batin PD, Andrews R, Lindsay SJ, Brooksby P, Mullen M, Baig W, Flapan AD, Cowley A, Prescott RJ, Neilson JMM, Fox KAA (1998) Prospective study of heart rate variability and mortality in chronic heart failure: results of the United Kingdom heart failure evaluation and assessment of risk trial (UK-Heart). Circulation 98:1510-1516

14. La Rovere MT, Bigger JT Jr, Marcus FI, Mortara A, Schwartz PJ (1998) Baroreflex sensitivity and heart-rate variability in prediction of total cardiac mortality after myocardial infarction. ATRAMI (autonomic tone and reflexes after myocardial infarction) investigators. Lancet 351:478-484

15. Kleiger RE, Miller JP, Bigger JT Jr, Moss AJ (1987) Decreased heart rate variability and its association with increased mortality after acute myocardial infarction. Am J Cardiol 59:256-262

16. Bigger JT Jr, Fleiss JL, Steinman RC, Rolnitzky LM, Kleiger RE, Rottman JN (1992) Frequency domain measures of heart period variability and mortality after myocardial infarction. Circulation 85:164-171

17. La Rovere M, Specchia G, Mortara A, Schwartz P (1988) Baroreflex sensitivity, clinical correlates, and cardiovascular 
mortality among patients with a first myocardial infarction. A prospective study. Circulation 78:816-824

18. Billman G, Schwartz P, Stone H (1982) Baroreceptor reflex control of heart rate: a predictor of sudden cardiac death. Circulation 66:874-880

19. De Ferrari GM, Vanoli E, Stramba-Badiale M, Hull SS, Foreman RD, Schwartz PJ (1991) Vagal reflexes and survival during acute myocardial ischemia in conscious dogs with healed myocardial infarction. Am J Physiol Heart Circ Physiol 261: H63-H69

20. Schwartz P, Vanoli E, Stramba-Badiale M, De Ferrari G, Billman G, Foreman R (1988) Autonomic mechanisms and sudden death. New insights from analysis of baroreceptor reflexes in conscious dogs with and without a myocardial infarction. Circulation 78:969-979

21. Cerati D, Schwartz P (1991) Single cardiac vagal fiber activity, acute myocardial ischemia, and risk for sudden death. Circ Res 69:1389-1401

22. Farrell TG, Odemuyiwa O, Bashir Y, Cripps TR, Malik M, Ward DE, Camm AJ (1992) Prognostic value of baroreflex sensitivity testing after acute myocardial infarction. Br Heart J 67(2):129-137

23. Farrell TG, Bashir Y, Cripps T, Malik M, Poloniecki J, Bennett ED, Ward DE, Camm AJ (1991) Risk stratification for arrhythmic events in postinfarction patients based on heart rate variability, ambulatory electrocardiographic variables and the signal-averaged electrocardiogram. J Am Col Cardiol 18:687697

24. Tuininga YS, van Veldhuisen DJ, Brouwer J, Haaksma J, Crijns HJ, Man in't Veld AJ, Lie KI (1994) Heart rate variability in left ventricular dysfunction and heart failure: effects and implications of drug treatment. Br Heart J72:509-513

25. Nolan J, Flapan AD, Capewell S, MacDonald TM, Neilson JM, Ewing DJ (1992) Decreased cardiac parasympathetic activity in chronic heart failure and its relation to left ventricular function. Br Heart J 67:482-485

26. Brodde OE, Bruck H, Leineweber K, Seyfarth T (2001) Presence, distribution and physiological function of adrenergic and muscarinic receptor subtypes in the human heart. Basic Res Cardiol 96:528-538

27. Brack KE, Coote JH, Ng GA (2010) Vagus nerve stimulation inhibits the increase in $\mathrm{Ca}^{2+}$ transient and left ventricular force caused by sympathetic nerve stimulation but has no direct effects alone-epicardial $\mathrm{Ca}^{2+}$ fluorescence studies using fura-2 $\mathrm{AM}$ in the isolated innervated beating rabbit heart. Exp Physiol 95:80-92

28. Rysevaite K, Saburkina I, Pauziene N, Vaitkevicius R, Noujaim SF, Jalife J, Pauza DH (2011) Immunohistochemical characterization of the intrinsic cardiac neural plexus in whole-mount mouse heart preparations. Heart Rhythm 8:731-738

29. Rysevaite K, Saburkina I, Pauziene N, Noujaim SF, Jalife J, Pauza DH (2011) Morphologic pattern of the intrinsic ganglionated nerve plexus in mouse heart. Heart Rhythm 8:448-454

30. Batulevicius D, Pauziene N, Pauza DH (2005) Architecture and age-related analysis of the neuronal number of the guinea pig intrinsic cardiac nerve plexus. Ann Anat 187:225-243

31. Johnson TA, Gray AL, Lauenstein JM, Newton SS, Massari VJ (2004) Parasympathetic control of the heart. I. An interventriculo-septal ganglion is the major source of the vagal intracardiac innervation of the ventricles. J Appl Physiol 96:2265-2272

32. Pauza DH, Skripka V, Pauziene N (2002) Morphology of the intrinsic cardiac nervous system in the dog: a whole-mount study employing histochemical staining with acetylcholinesterase. Cells Tissues Organs 172:297-320

33. Ulphani JS, Cain JH, Inderyas F, Gordon D, Gikas PV, Shade G, Mayor D, Arora R, Kadish AH, Goldberger JJ (2010)
Quantitative analysis of parasympathetic innervation of the porcine heart. Heart Rhythm 7:1113-1119

34. Saburkina I, Rysevaite K, Pauziene N, Mischke K, Schauerte P, Jalife J, Pauza DH (2010) Epicardial neural ganglionated plexus of ovine heart: anatomic basis for experimental cardiac electrophysiology and nerve protective cardiac surgery. Heart Rhythm 7:942-950

35. Pauza DH, Skripka V, Pauziene N, Stropus R (2000) Morphology, distribution, and variability of the epicardiac neural ganglionated subplexuses in the human heart. Anat Rec 259: 353-382

36. Kawano H, Okada R, Yano K (2003) Histological study on the distribution of autonomic nerves in the human heart. Heart Vessels 18:32-39

37. Armour JA (1996) Anatomy and function of peripheral autonomic neurons involved in cardiac regulation. In: Shepard VT, Vatner SF (eds) Nervous control of the heart, 1st edn. Harwood academic publishers, London, pp 29-48

38. Ng GA, Brack KE, Coote JH (2001) Effects of direct sympathetic and vagus nerve stimulation on the physiology of the whole heart-a novel model of isolated Langendorff perfused rabbit heart with intact dual autonomic innervation. Exp Physiol $86: 319$

39. Ardell JL, Randall WC (1986) Selective vagal innervation of sinoatrial and atrioventricular nodes in canine heart. Am $\mathrm{J}$ Physiol 251:H764-H773

40. Armour JA (1976) Instant to instant reflex cardiac regulation. Cardiology 61:309-328

41. Armour JA (2008) Potential clinical relevance of the 'little brain' on the mammalian heart. Exp Physiol 93:165-176

42. Huang MH, Wolf SG, Armour JA (1994) Ventricular arrhythmias induced by chemically modified intrinsic cardiac neurones. Cardiovasc Res 28:636-642

43. Bibevski S, Dunlap M (1999) Evidence of impaired vagus nerve activity. Heart Failure 99(22):2958-2963

44. Dhein S, van Koppen CJ, Brodde O (2001) Muscarinic receptors in the mammalian heart. Pharmacol Res 44:161-182

45. Stengel PW, Gomeza J, Wess J, Cohen ML (2002) M2 and M4 receptor knockout mice: muscarinic receptor function in cardiac and smooth muscle in vitro Pharmacol Exp Therap 292:877-885

46. Olshansky B, Sabbah HN, Hauptman PJ, Colucci WS (2008) Parasympathetic nervous system in heart failure: pathophysiology and potential implications for therapy. Circulation 118:862-871

47. Hoover DB, Baisden RH, Xi-Mov SX (1994) Localization of muscarinic receptors mRNAs in rat heart and intrinsic ganglia by in situ hybridisation. Circ Res 75:813-820

48. Karasawa Y, Furukawa Y, Ren LM, Takei M, Murakami M, Narita M, Chiba S (1990) Cardiac responses to VIP and VIPergic-cholinergic interaction in isolated dog heart preparations. Eur J Pharmacol 187:9-17

49. Einbrodt (1859) Ueber Herzreizung und ihr Verhaeltnis zum Blutdruck. Akademie der Wissenschaften (Vienna) Sitzungsberichte 38:345

50. Scherlag BJ, Helfant RH, Haft JI, Damato AN (1970) Electrophysiology underlying ventricular arrhythmias due to coronary ligation. Am J Physiol 219:1665-1671

51. Goldstein RE, Karsh RB, Smith ER, Orlando M, Norman D, Farnham G, Redwood DR, Epstein SE (1973) Influence of atropine and of vagally mediated bradycardia on the occurrence of ventricular arrhythmias following acute coronary occlusion in closed-chest dogs. Circulation 47:1180-1190

52. Myers RW, Pearlman AS, Hyman RM, Goldstein RA, Kent KM, Goldstein RE, Epstein SE (1974) Beneficial effects of vagal stimulation and bradycardia during experimental acute myocardial ischemia. Circulation 49:943-947 
53. Waxman H, Cain M, Greenspan A, Josephson M (1982) Termination of ventricular tachycardia with ventricular stimulation: salutary effect of increased current strength. Circulation 65:800-804

54. Kolman B, Verrier R, Lown B (1975) The effect of vagus nerve stimulation upon vulnerability of the canine ventricle: role of sympathetic-parasympathetic interactions. Circulation 52:578-585

55. Yoon MS, Han J, Tse WW, Rogers R (1977) Effects of vagal stimulation, atropine, and propranolol on fibrillation threshold of normal and ischemic ventricles. Am Heart J 93:60-65

56. Kent KM, Smith ER, Redwood DR, Epstein SE (1973) Electrical stability of acutely ischemic myocardium. Influences of heart rate and vagal stimulation. Circulation 47:291-298

57. Corr PB, Gillis RA (1974) Role of the vagus in the cardiovascular changes induced by coronary artery occlusion. Circulation 49:86-97

58. Zuanetti G, De Ferrari GM, Priori SG, Schwartz PJ (1987) Protective effect of vagal stimulation on reperfusion arrhythmias in cats. Circ Res 61:429-435

59. Schwartz PJ, Billman GE, Stone HL (1984) Autonomic mechanisms in ventricular fibrillation induced by myocardial ischemia during exercise in dogs with healed myocardial infarction. An experimental preparation for sudden cardiac death. Circulation 69:790-800

60. Vanoli E, De Ferrari GM, Stramba-Badiale M, Hull SS Jr, Foreman RD, Schwartz PJ (1991) Vagal stimulation and prevention of sudden death in conscious dogs with a healed myocardial infarction. Circ Res 68:1471-1481

61. Weiss JN, Chen P-S, Qu Z, Karagueuzian HS, Garfinkel A (2000) Ventricular fibrillation: how do we stop the waves from breaking? Circ Res 87:1103-1107

62. Cao JM, Qu Z, Kim YH, Wu TJ, Garfinkel A, Weiss JN, Karagueuzian HS, Chen PS (1999) Spatiotemporal heterogeneity in the induction of ventricular fibrillation by rapid pacing: importance of cardiac restitution properties. Circ Res 84:1318-1331

63. Nolasco JB, Dahlen RW (1968) A graphic method for the study of alternation in cardiac action potentials. J Appl Physiol 25: 191-196

64. Karma A (1994) Electrical alternans and spiral wave breakup in cardiac tissue. Chaos 4(3):461-472

65. Gilmour RF Jr, Chialvo DR (1999) Electrical restitution, critical mass, and the riddle of fibrillation. J Cardiovasc Electrophysiol 10:1087-1089

66. Garfinkel A, Kim YH, Voroshilovsky O, Qu Z, Kil JR, Lee MH, Karagueuzian HS, Weiss JN, Chen PS (2000) Preventing ventricular fibrillation by flattening cardiac restitution. Proc Natl Acad Sci 97:6061-6066

67. Riccio ML, Koller ML, Gilmour RF Jr (1999) Electrical restitution and spatiotemporal organization during ventricular fibrillation. Circ Res 84:955-963

68. Ng GA, Brack KE, Patel VH, Coote JH (2007) Autonomic modulation of electrical restitution, alternans and ventricular fibrillation initiation in the isolated heart. Cardiovasc Res 73:750-760

69. Wei SK, Ruknudin AM, Shou M, McCurley JM, Hanlon SU, Elgin E, Schulze DH, Haigney MC (2007) Muscarinic modulation of the sodium-calcium exchanger in heart failure. Circulation 115(10): 1225-1233

70. Laurita KR, Girouard SD, Akar FG (1998) Modulated dispersion explains changes in arrhythmia vulnerability during premature stimulation of the heart. Circulation 98:2774-2780

71. Marshall RJ, Muir AW, Winslow E (1983) Effects of antiarrhythmic drugs on ventricular fibrillation thresholds of normal and ischaemic myocardium in the anesthetise rat. $\mathrm{Br} \mathrm{J}$ Pharmacol 78:165-171
72. Harumi K, Tsutsumi T, Sato T, Sekiya S (1989) Classification of antiarrhythmic drugs based on ventricular fibrillation threshold Am J Cardiol 64:10J-14J

73. Podrid PJ, Myerburg RJ (2005) Epidemiology and stratification of risk for sudden cardiac death. Clin Cardiol 28(Supp 1):I3-I11

74. Maskin CS, Siskind SJ, LeJemtel TH (1984) High prevalence of nonsustained ventricular tachycardia in severe congestive heart failure. Am Heart J 107:896-901

75. Zheng C, Li M, Inagaki M, Kawada T, Sunagawa K, Sugimachi M (2005) Vagal stimulation markedly suppresses arrhythmias in conscious rats with chronic heart failure after myocardial infarction. Conf Proc IEEE Eng Med Bio Soc 7:7072-7075

76. Sabbah HN (2011) Electrical vagus nerve stimulation for the treatment of chronic heart failure. Cleavland Clin J Med 78(supp 1):S24-S29

77. Wang X, Gerdes AM (1999) Chronic pressure overload cardiac hypertrophy and failure in guinea pigs: III. Intercalated disc remodelling. J Mol Cell Cardiol 31:333-343

78. Ai X, Pogwizd SM (2005) Connexin 43 downregulation and dephosphorylation in nonischemic heart failure is associated with enhanced colocalized protein phosphatase type 2A. Circ Res 96:54-63

79. Behling A, Moraes RS, Rohde LE, Ferlin EL, Nobrega AC, Ribeiro JP (2003) Cholinergic stimulation with pyridostigmine reduces ventricular arrhythmia and enhances heart rate variability in heart failure. Am Heart J 146(3):495-500

80. Zhang YH, Song YC (1998) Suppressing sympathetic activation with clonidine on ventricular arrhythmias in congestive heart failure. Int J Cardiol 65:233-238

81. Li M, Zheng C, Sato T, Kawada T, Sugimachi M, Sunagawa K (2004) Vagal nerve stimulation markedly improves long-term survival after chronic heart failure in rats. Circ 109:120-124

82. Zhang Y, PopoviÄ ZB, Bibevski S, Fakhry I, Sica DA, Van Wagoner DR, Mazgalev TN (2009) Chronic Vagus nerve stimulation improves autonomic control and attenuates systemic inflammation and heart failure progression in a canine high-rate pacing model/clinical perspective. Circ Heart Fail 2:692-699

83. Sabbah HN Electrical vagus nerve stimulation for the treatment of chronic heart failure. Cleve Clin J Med 78(Suppl 1):S24-S29

84. Sabbah HN, Rastogi S, Mishra S, Gupta RC, Ilsar I, Imai M, Cohen U, Ben-David T, Ben-Ezra O (2005) Long-term therapy with neuroselective electric Vagus nerve stimulation improves LV function and attenuates global LV remodelling in dogs with chronic heart failure. Eur J Heart Fail Suppl 4(Suppl):166-167

85. De Ferrari GM, Schwartz PJ Vagus nerve stimulation: from preclinical to clinical application: challenges and future directions. Heart Fail Rev 16:195-203

86. Samaan A (1935) The antagonistic cardiac nerves and heart rate. J Physiol 83(3):332-340

87. Levy MN, Zieske H (1969) Effect of enhanced contractility on the left ventricular response to vagus nerve stimulation in dogs. Circ Res 24:303-311

88. Martin PJ, Levy MN, Zieske H (1969) Analysis and simulation of the left ventricular response to autonomic nervous activity. Cardiovasc Res 3:396-410

89. Levy MN, Blattberg B (1976) Effect of vagal stimulation on the overflow of norepinephrine into the coronary sinus during cardiac sympathetic nerve stimulation in the dog. Circ Res 38: $81-84$

90. Brack KE, Coote JH, Ng GA (2004) Interaction between direct sympathetic and vagus nerve stimulation on heart rate in the isolated rabbit heart. Exp Physiol 89:128-139

91. Muscholl E (1980) Peripheral muscarinic control of norepinephrine release in the cardiovascular system. Am J Physiol 239:H713-H720 
92. Stiles GL, Caron MG, Lefkowitz RJ (1984) Beta-adrenergic receptors: biochemical mechanisms of physiological regulation. Physiol Rev 64:661-743

93. Murad F, Chi YM, Rall TW, Sutherland EW (1962) Adenyl cyclase. III. The effect of catecholamines and choline esters on the formation of adenosine $3^{\prime}, 5^{\prime}$-phosphate by preparations from cardiac muscle and liver. J Biol Chem 237:1233-1238

94. Vincent NH, Ellis S (1963) Inhibitory effect of acetylcholine on glycogenolysis in the isolated guinea-pig heart. J Pharmacol Exp Ther 139:60-68

95. Potter EK (1988) Neuropeptide $\mathrm{Y}$ as an autonomic neurotransmitter. Pharmacol Ther 37(2):251-273

96. Warner MR, Senanayake PD, Ferrario CM, Levy MN (1991) Sympathetic stimulation-evoked overflow of norepinephrine and neuropeptide Y from the heart. Circ Res 69(2):455-465

97. Warner MR, Levy MN (1990) Sinus and atrioventricular nodal distribution of sympathetic fibers that contain neuropeptide $\mathrm{Y}$. Circ Res 67(3):713-721

98. Warner MR, Levy MN (1989) Inhibition of cardiac vagal effects by neurally released and exogenous neuropeptide Y. Circ Res 65(6): 1536-1546

99. Warner MR, Levy MN (1989) Neuropeptide Y as a putative modulator of the vagal effects on heart rate. Circ Res 64(5): 882-889

100. Herring N, Lokale MN, Danson EJ, Heaton DA, Paterson DJ (2008) Neuropeptide Y reduces acetylcholine release and vagal bradycardia via a Y2 receptor-mediated, protein kinase C-dependent pathway. J Mol Cell Cardiol 44:477-485

101. Anderson FL, Kralios AC, Hershberger R, Bristow MR (1988) Effect of vasoactive intestinal peptide on myocardial contractility and coronary blood flow in the dog: comparison with isoproterenol and forskolin. J of Cardiovasc Pharmacol 12:365371

102. Wetzel GT, Brown JH (1985) Presynaptic modulation of acetylcholine release from cardiac parasympathetic neurons. Am J Physiol 248:H33-H39

103. Wetzel GT, Goldstein D, Brown JH (1985) Acetylcholine release from rat atria can be regulated through an alpha 1-adrenergic receptor. Circ Res 56:763-766

104. Brack KE, Coote JH, Ng GA (2011) Vagus nerve stimulation protects against ventricular fibrillation independent of muscarinic receptor activation. Cardiovasc Res 91:437-446

105. Jaiswal N, Lambrecht G, Mutschler E, Malik KU (1989) Effect of M2muscarinic receptor antagonist 4-DAMP, on prostaglandin synthesis and mechanical function in the isolated rabbit heart. Gen Pharmacol 20:497-502

106. Wang H, Wang Z (2007) Function of cardiac M3 receptors. Auton Autocoid Pharamcol 27:1-11

107. Liu Y, Sung HL, Wang LY, Goa Y, Wang YP, Du ZM, Lu YJ, Yang BF (2008) Choline produces antiarrhythmic actions in animal models by cardiac M3 receptors: improvement of intracellular $\mathrm{Ca}^{2+}$ handling as a common mechanism. Can J Physiol Pharmacol 86:860-865

108. Liu Y, Sun L, Pan Z, Bai Y, Wang N, Zhao J, Xu C, Li Z, Li B, Du Z, Lu Y, Gao X, Yang B (2011) Overexpression of $\mathrm{m}(3)$ muscarinic receptors is a novel strategy for preventing sudden cardiac death in transgenic mice. Mol Med 17(11-12):11791187

109. Liu Y, Xu C, Jiao J, Wang H, Dong D, Yang B (2005) M3-R/ IKM3 - a new target of antiarrhythmic agents. Acta Pharmace Sinica 40:8-12

110. Wang S, Han H, Jiang Y, Wang C, Song H, Pan Z, Fan K, Du J, Fan Y, Du Z, Liu Y (2012) Activation of cardiac M3 Muscarinic acetylcholine has cardioprotective effects against ischemiainduced arrhythmias. Clin Exp Pharmacol Physiol 39(4):343349
111. Ando M, Katare RG, Katinuma Y, Zhang D, Yamasaki F, Muramoto, Sato T (2005) Efferent vagal nerve stimulation protects the heart against ischemia-induced arrhythmias by preserving connexin43 protein 112:164-170

112. Martins JB, Zipes DP (1980) Effects of sympathetic and vagal nerves on recovery properties of the endocardium and epicardium of the canine left ventricle. Circ Res 46:100-110

113. Mantravadi R, Gabris B, Liu T, Choi BR, de Groat WC, Ng GA, Salama G (2007) Autonomic nerve stimulation reverses ventricular repolarization sequence in rabbit hearts. Circ Res 100: e $72-\mathrm{e} 80$

114. Vaillant F, Timour Q, Descotes J, Manati W, Belhani D, BuiXuan B, Tabib A, Bricca G, Chevalier P (2008) Ivabradine induces an increase in ventricular fibrillation threshold during acute myocardial ischemia: an experimental study. J Cardiovasc Pharmacol 52:548-554

115. Koncz I, Szél T, Bitay M, Cerbai E, Jaeger K, Fülöp F, Jost N, Virág L, Orvos P, Tálosi L, Kristóf A, Baczkó I, Papp JG, Varró A (2011) As Electrophysiological effects of ivabradine in dog and human cardiac preparations: potential antiarrhythmic actions. Eur J Pharmacol 668:419-426

116. Tavazzi L (2003) Heart rate as a therapeutic target in heart failure? Eur Heart J 5(Supp G):G15-G18

117. Weidmann S (1952) The electrical constants of Purkinji fibres. J Physiol 118(3):348-360

118. Singh BN, Sarma JS, Zhang ZH, Takanaka C (1992) Controlling cardiac arrhythmia by lengthening repolarisation: rationale from experimental and clinical considerations. Ann NY Acad Sci 644:187-209

119. Singh BN (1993) Arrythymia control by prolonging repolarisation: the concept and its potential therapeutic impact. Eur Heart J 14:14-23

120. Kuo C, Munakata K, Reddy C, Surawicz B (1983) Characteristics and possible mechanism of ventricular arrhythmia dependent on the dispersion of action potential durations. Circulation 67:1356-1367

121. Winter J, Tanko AS, Brack KE, Coote JH, Ng GA (2011) Differential cardiac responses to unilateral sympathetic nerve stimulation in the isolated innervated rabbit heart. Auton Neurosci Basic Clinical 166:4-14

122. Angelakos ET (1965) Regional distribution of catecholamines in the dog heart. Circ Res 16:39-44

123. Kawano H, Okada R, Yano K (2003) Histological study on the distribution of autonomic nerves in the human heart. Heart Vessels 18:32-39

124. Moncada S, Palmer RM, Higgs EA (1991) Nitric oxide: physiology, pathophysiology, and pharmacology. Pharmacol Rev 43:109-142

125. Massion PB, Feron O, Dessy C, Balligand J-L (2003) Nitric oxide and cardiac function. Circ Res 93:388-398

126. Lundberg JO, Weitzberg E, Gladwin MT (2008) The nitratenitrite-nitric oxide pathway in physiology and therapeutics. Nat Rev Drug Discov 7:156-167

127. Guix FX, Uribesalgo I, Coma M, Muňoz FJ (2005) The physiology and pathophysiology of nitric oxide in the brain. Progr Neurobiol 76:126-152

128. Grundy D, Schemann M (2007) Enteric nervous system. Curr Opin Gastroenterol 23(2):121-126

129. Conlon K, Kidd C (1999) Neuronal nitric oxide facilitates vagal chronotropic and dromotropic actions on the heart. J Auton Nerv Syst 75:136-146

130. Herring N, Golding S, Paterson DJ (2000) Pre-synaptic NOcGMP pathway modulates vagal control of heart rate in isolated adult guinea pig atria. J Mol Cell Cardiol 32:1795-1804

131. Brack KE, Patel VH, Coote JH, Ng GA (2007) Nitric oxide mediates the vagal protective effect on ventricular fibrillation 
via effects on action potential duration restitution in the rabbit heart. J Physiol 583:695-704

132. Kumar K, Nguyen K, Waxman S, Nearing BD, Wellenius GA, Zhao SX, Verrier RL (2003) Potent antifibrillatory effects of intrapericardial nitroglycerin in the ischemic porcine heart. J Am Coll Cardiol 41:1831-1837

133. Patel VH, Brack KE, Coote JH, Ng GA (2004) The effect of nitric oxide on electrical restitution and ventricular fibrillation in the isolated rabbit heart: mechanism underlying the antifibrillatory effects of vagus nerve activity. Eur Heart J 25:68 (ABSTRACT)

134. Brack KE, Patel VH, Mantravardi R, Coote JH, Ng GA (2009) Direct evidence of nitric oxide release from neuronal nitric oxide synthase activation in the left ventricle as a result of cervical vagus nerve stimulation. J Physiol 587:3045-3054

135. Jumrussirikul P, Dinerman J, Dawson TM, Dawson VL, Ekelund U, Georgakopoulos D, Schramm LP, Calkins H, Snyder SH, Hare JM, Berger RD (1998) Interaction between neuronal nitric oxide synthase and inhibitory $\mathrm{G}$ protein activity in heart rate regulation in conscious mice. J Clin Investig 102:1279-1285

136. Jones JFX (2009) Cardiac defibrillator neurones. J Physiol $587: 2715$

137. Singh S, Gray T, Wurster RD (2009) Nitric oxide and carbon monoxide synthesizing enzymes and soluble guanylyl cyclase within neurons of adult human cardiac ganglia. Auton Neurosci Basic Clinical 145:93-98

138. Pupo AS, Minneman KP (2002) Interaction of neuronal nitric oxide synthase with alpha1-adrenergic receptor subtypes in transfected HEK-293 cells. BMC Pharmacol 2:17

139. Hoover DB, Isaacs ER, Jaques F, Hoard JL, Page P, Armour JA (2009) Localization of multiple neurotransmitters in surgically derived specimens of human atrial ganglia. Neuroscience 164(3):1170-1179

140. Tracey KJ (2001) The inflammatory reflex. Nature 420:853-859
141. Wang H, Yu M, Ochani M, Amella CA, Tanovic M, Susarla S, Li JH, Wang H, Yang H, Ulloa L, Al-Abed Y, Czura CJ, Tracey KJ (2003) Nicotinic acetylcholine receptor [alpha]7 subunit is an essential regulator of inflammation. Nature 421:384-388

142. Li W, Olshansky B (2011) Inflammatory cytokines and nitric oxide in heart failure and potential modulation by vagus nerve stimulation. Heart Fail Rev 16:137-145

143. Sloan RP, McCreath H, Tracey KJ, Sidney S, Liu K, Seeman T (2007) RR interval variability is inversely related to inflammatory markers: the CARDIA study. Mol Med 13:178-184

144. Corrado D, Basso C, Thiene G (2001) Sudden cardiac death in young people with apparently normal heart. Cardiovasc Res 50:399-408

145. Chugh SS, Kelly KL, Titus JL (2000) Sudden cardiac death with apparently normal heart. Circulation 102:649-654

146. Klein RM, Vester EG, Brehm MU, Dees H, Picard F, Niederacher D, Beckmann MW, Strauer BE (2000) Inflammation of the myocardium as an arrhythmia trigger. Z Kardiol 89(Suppl 3):24-35

147. London B, Baker LC, Lee JS, Shusterman V, Choi B-R, Kubota T, McTiernan CF, Feldman AM, Salama G (2003) Calciumdependent arrhythmias in transgenic mice with heart failure. Am J Physiol Heart Circ Physiol 284:H431-H441

148. Janczewski AM, Kadokami T, Lemster B, Frye CS, McTiernan CF, Feldman AM (2003) Morphological and functional changes in cardiac myocytes isolated from mice overexpressing TNF- $\alpha$. Am J Physiol Heart Circ Physiol 284:H960-H969

149. Petkova-Kirova PS, Gursoy E, Mehdi H, McTiernan CF, London B, Salama G (2006) Electrical remodeling of cardiac myocytes from mice with heart failure due to the overexpression of tumor necrosis factor-alpha. Am J Physiol Heart Circ Physiol 290:H2098-H2107

150. Taggart P, Critchley H, Lambiase PD (2011) Heart-brain interactions in cardiac arrhythmia. Heart 97(9):698-708 